NBER WORKING PAPER.SERIES

\title{
ON THE TIMING AND EFFICIENCY OF CREATIVE DESTRUCTION
}

Ricardo J. Caballero

Mohamad L. Hammour

Working Paper No. 4768

\author{
NATIONAL BUREAU OF ECONOMIC RESEARCH \\ 1050 Massachusetts Avenue \\ Cambridge, MA 02138 \\ June 1994
}

We are grateful to David Gross for excellent research assistance, and to Daron Acemoglu, Olivier Blanchard, Peter Diamond, Thomas Piketty, Julio Rotemberg and workshop participants at DELTA, lowa, Northwestern, Pennsylvania, Paris I, Western Ontario and the NBER EFCC meetings for helpful comments. Ricardo Caballero thanks the National Science and Alfred P. Sloan foundations for their financial support. Part of this paper was written while Mohamad Hammour was visiting at DELTA. This paper is part of NBER's research program in Economic Fluctuations. Any opinions expressed are those of the authors and not those of the National Bureau of Economic Research. 
NBER Working Paper \#4768

June 1994

\title{
ON THE TIMING AND EFFICIENCY \\ OF CREATIVE DESTRUCTION
}

\begin{abstract}
This paper analyzes the timing, pace and efficiency of the on-going job reallocation that results from product and process innovation. There are strong reasons why an efficient economy ought to concentrate both job creation and destruction during cyclical downturns, when the opportunity cost of reallocation is lowest. Malfunctioning labor markets can disrupt this synchronized pattem and decouple creation and destruction. Moreover, irrespective of whether workers are too strong or too weak, labor market inefficiencies generally lead to technological "sclerosis," characterized by excessively slow renovation. Government incentives to production may alleviate high unemployment in this economy, but at the cost of exacerbating sclerosis. Creation incentives, on the contrary, increase the pace of reallocation. We show how an optimal combination of both types of policies can restore economic efficiency.
\end{abstract}

Ricardo J. Caballero

Department of Economics

Room E52-252g

Massachusetts Institute of Technology

Cambridge, MA 02139

and NBER
Mohamoud L. Hammour Department of Economics Columbia University 420 West 118th Street New York, NY 10027 


\section{Introduction}

When technology, in its broadest sense, is embodied in capital, skills, and the organization of work, technical progress puts the economy in a state of incessant restructuring. Its productive structure must constantly adapt to innovations in products, techniques, modes of organization, and to the evolving competitiveness of world markets. Production units that embody new techniques must continually be created, while outdated units must be destroyed.

This process of growth through Schumpeterian "creative destruction" results in an ongoing reallocation of factors of production from contracting production sites to expanding ones. ${ }^{1}$ This idea finds strong support in recent studies of productivity growth using plant-level LRD data. Baily, Hulten and Campbell (1992) and Bartelsman and Dhrymes (1991) decompose improvements in aggregate productivity into a component due to resource reallocation from relatively inefficient to relatively efficient plants, and another due to improvements in technology purely at the plant level. ${ }^{2}$ Both studies find that

\footnotetext{
${ }^{1}$ See Schumpeter (1942). Cox and Alm (1993) provide numerous illustrations of creative destruction at work in the US economy.

'A related question, that focuses on physical as opposed to human or organizational capital, is how much of output growth is asociated with capitalembodied technological progress. Using post-war US data, Hulten (1992) estimates that $20 \%$ of residual manufacturing output growth is capital-embodied while Greenwood, Herkowits and Krusell (1992) reach a figure of $60 \%$ for the growth of aggregate output per hour. The difference between the results is mainly due to whether gross-output or value-added data are used to measure the share of equipment in income, and whether output should be adjusted for quality change.

The much earlier etudy by Salter (1960) of the distribution of productivity across plants should also be mentioned. It provides rich microeconomic evidence from the U.K. and U.S. supporting the heterogeneous microeconomic structure and renovation process implied by the embodied nature of technical progress.

Some examples of this evidence give a favor of the study. In his table 1, for example, Salter describes the "best and average practice" labor productivity in the U.S. blast-furnace industry: In 1911 the best-practice plants produced 0.313 tons of pig-iron per man-hour, against an average across plants of 0.140 . By 1926 these numbers had increased to 0.573 and 0.296 , respectively.

Many other examples of aubstantial heterogeneity in productivity within an industry can be found in table 8. In the U.S. beet sugar industry, e.g., man-hours per unit of output (in tons) ranged form 2.81 to 0.88 in 1935. Moreover, plant age is strongly related to productivity in this industry. Table 9 shows that average man-hout per ton was 2.08 for plants constructed during 1890-99, 1.74 for 1900-09 plants, 1.42 for 1910-19 plants, and 1.26 for $1920-29$ plants.

More direct evidence on the embodiment issue is found in table 11. 1t reports for several U.S. industries the increase in productivity between 1939 and 1948 for plants that implemented large changes in equipment.
} 
a major part of technical progress is associated with factor reallocation. Compounded over the period 1972-1987 for a sample of 22 industries, the results in Baily et al. (1992) indicate that aggregate growth is made up of 6.7 percentage points due to reallocation and 3.5 points due to plant-level technical progress. ${ }^{3}$

Thus, ongoing creative destruction often entails distressing job losses, and can therefore result in a political response to protect those jobs. If job reallocation is an inescapable requisite of the progress in standards of living, policies that are overly protective of existing jobs may hinder the pace of renovation and lead to technological "sclerosis." But laissez-faire may be equally deficient. The massive job destruction that takes place in a recession, for example, may be the sign of chronically malfunctioning markets, rather than an aspect of the healthy recycling of jobs.

This paper aims at improving our understanding of the characteristics of an efficiently functioning creative destruction process, of the way market inefficiencies can disrupt this process, and of appropriate policy responses to such disruptions. We show how malfunctioning labor and goods markets can disrupt the timing and volatility of creative destruction over the cycle, and hamper the pace of renovation in the economy. We analyze the effect of government incentives to production and creation decisions, and show how an optimal combination of both types of policies can restore full efficiency.

Section 2 presents our basic model. Our economy experiences ongoing exogenous technical progress. Its productive structure embodies the best techniques available at the time of creation, and must continually be restructured to incorporate new innovations. Both the labor and goods markets function inefficiently. The labor market is deprived of the benefits of a Walrasian auctioneer, and is characterized instead by decentralized bargaining between workers and firms. Inefficiency in the goods market is introcluced through a distortion in the profitability of firms, which can either be interpreted literally

methoda and plant layout, versus those that did not. The former increased their productivily by an average of 17 percent during the period, while the latter increased productivity by less than 1 percent on average.

${ }^{3}$ Results for "All industries except 3573," table 1, p. 207. 
as the result of distortionary taxation or more loosely as capturing the effect of "aggregate demand" on profitability. To study the cyclical timing of creative destruction, we subject the economy to exogenous fluctuations in proft margins, which may either be "real" due to fluctuations in the price of intermediate inputs - or due to fluctuations in the above-mentioned aggregate-demand distortion.

Section 3 focuses on cyclical aspects of creative destruction. We contrast the cyclical response of an efficient economy with an inefficient economy in terms of observable characteristics of timing and volatility of creation, destruction and unemployment. In our efficient economy, the sole role of unemployment is to facilitate labor reallocation. An efficiently restructuring economy will concentrate reallocation in recessions, when the opportunity cost of unemployment is lowest. Thus both job destruction and creation rise in a recession to increase labor reallocation. We show that market inefficiencies can disrupt this tightly synchronized pattern and decouple creation and destruction.

Section 4 turns to the effect of labor market inefficiencies on the pace of the creative destruction process. Under what conditions will the restructuring of the productive system be excessively sluggish, and result in technological "sclerosis"? When will restructuring be, on the contrary, wastefully rapid, and result in what one might call technological "hyperkinesis"? Surprisingly, we find that, irrespective of whether workers are excessively weak or strong, labor market inefficiencies in either direction always lead to sclerosis.

Finally, section 5 analyzes policy. In the absence of an institutional cure for labormarket failures, we look at the effect of government incentives to production and creation decisions. Expanding the economy through production incentives can reduce unemployment, but at the cost of exacerbating sclerosis. Could the latter effect more than offset the welfare benefits of the former, rendering desirable - as the pre-Keynesian "liquidationist" view has it - a contraction that "cleanses" the productive structure? We argue against this possibility, and show that, as long as more unemployment is undesirable, creating a contraction cannot be beneficial on the whole. An expansion driven by creation subsidies, on the other hand, has the opposite effect of alleviating sclerosis as it acceler- 
ates the pace of reallocation. A small dose of creation subsidies can thus be beneficial, but a large dose can lead to excessively rapid restructuring of the type documented by Young (1992) in the case of Singapore. We show that it is through an optimal dynamic combination of both types of policies that the economy can recover its full efficiency.

Relation to the Literature. Our paper relates to several strands of research in the literature. A rich body of research developed in the 1960s that analyzes steady-state creative destruction in a vintage model of embodied technological progress (see, e.g., Johansen 1959, Solow 1960, Phelps 1963, Sheshinski 1967). More recent analyses of creative destruction in an endogenous-growth vein can be found in Aghion and Howitt (1992a) and Grossman and Helpman (1991). Our paper addresses the question of efficiency of the creative destruction process, and analyzes how market failures can disrupt the pace of reallocation and lead to distorted unemployment rates. In this last respect, it is related to the work of Cox (1993) and Cohen and Saint-Paul (1994), who analyze structural factors by which embodied technological progress leads to "technological unemployment," and to Aghion and Howitt (1992b), who study the effect of different rates of technical progress on steady-state unemployment.

An important dimension of our analysis concerns out-of-steady-state business cycle issues. Mortensen and Pissarides (1993) and Mortensen (1993) use a search unemployment framework to interpret the evidence on gross job flows over the cycle uncovered by Davis and Haltiwanger $(1990,1992)$ and Blanchard and Diamond (1990). Although their focus on search costs in firm-worker bargaining leads to useful insights, we argue below that shifting the emphasis to specific investment costs along the lines of Caballero and Hammour (1994) is a more promising avenue in providing a satisfactory interpretation of the facts.

Our work also raises an important warning for the literature on the role of allocative vs. aggregate disturbances in driving employment fluctuations (Lilien 1982, Abraham and Katz 1986, Blanchard and Diamond 1989, Davis and Haltiwanger 1994). Contrary to the standard identifying assumption in the literature, aggregate shocks in our model 
have a reallocation effect and can therefore not be considered independent of reallocation shocks. 'Moreover, the economy's response to aggregate shocks can look like the response used to identify allocative shocks in the literature. Depending on bargaining parameters in the economy, creation and destruction can be either positively or negatively correlated and the Beveridge curve can be upward or downward sloping.

Our efficiency analysis of creative destruction over the cycle revisits the literature on reorganizations (Davis and Haltiwanger 1990, Hall 1990, Cooper and Haltiwanger 1992, Aghion and Saint-Paul 1991, Gali and Hammour 1991, Saint-Paul 1993) and shakeouts (Caballero and Hammour 1994, Stiglitz 1993, Bresnahan and Raff 1991 and 1992) during recessions. We attempt to relate questions on the efficiency of reorganization over the cycle to observable characteristics of the data, and ask whether a recession that cleanses the productive structure can be beneficial on the whole.

The analysis of government policy in the literature is often neglected. An exception is Hopenhayn and Rogerson (1991), who quantify the negative welfare-effects of policy in a steady-state competitive industry subject to ongoing job turnover. Our paper also tries to develop a substantive analysis of policy in a context where, because of market failures, policy can play a positive as well as a negative role.

\section{A Renovating Economy}

Our first step is to present the model we will be using to analyze creative destruction throughout the paper. We first describe the basic structure of our model economy. The next two subsections characterize, in turn, the efficient centrally planned outcome and the decentralized bargaining equilibrium. The last subsection asks under what conditions the decentralized economy is efficient.

\footnotetext{
'A similar point is made by Abraham and Katz (1986) concerning Lilien's finding that employment growth dispersion acroes sectors tends to be high when unemployment is high. They argue that this can
be due aggregate demand rather than reallocation shocks, if we consider the different income-elasticities of demand and different growth rates across sectors.
} 


\subsection{The Economy}

Productive Structure. The economy trades in two goods: a produced good whose aggregate output at time $t$ is $Q(t)$, and a non-produced good in fixed supply $\bar{M}$. Its productive structure is made up of many "production units" that combine in fixed proportions a unit of capital, a unit of labor, and a unit of the non-produced good as an intermediate input. Exogenous technical progress is embodied in production units and drives the continuous process of their creation and destruction. Abstracting away from "learning curve" effects, we assume that a production unit embodies the leading technology at the time $t$ when it was created and produces $A(t)$ units of output, where the leading technology grows exogenously at rate $\gamma>0.5$

Each production unit corresponds to a "job." The creation rate of new production units corresponds to the gross hiring rate in the economy, and is denoted by $H(t)$. Production units in operation fail exogenously at rate $\delta$, and are scrapped beyond a certain endogenously determined age. Both events free up a unit of labor.

If we denote by $\bar{a}(t)$ the age of the oldest unit in operation, it is clear from the above that aggregate employment $E(t)$ and output $Q(t)$ are determined by the distribution of production units aged between 0 and $\bar{a}(t)$ :

$$
\begin{gathered}
E(t)=\int_{0}^{a(t)} H(t-a) e^{-\delta a} d a . \\
Q(t)=\int_{0}^{\bar{a}(t)} A(t-a) H(t-a) e^{-\delta a} d a .
\end{gathered}
$$

Creation Costs: Creating a production unit is costly. It requires acquiring and installing capital, searching for a worker, training him and organizing his job. In many respects, this fact plays a determining role in our economy. In the absence of creation

\footnotetext{
'Jovanovic and Lach (1989) study an industry's long-run equilibrium in the presence of both vintage and learning-by-doing effects. It would be straightforward to endogenize the growth rate $\gamma$, but, to keep the paper focused, we decided not to exploit this dimension.
} 
costs, technology would be updated instantaneously and the distribution of production units would be degenerate. Moreover, the bargaining problem between workers and firms depends on the magnitude of those costs, their timing and the extent to which they are "sunk." Finally, as we will see, the structure of creation costs is crucial for the responsiveness of creation, destruction and unemployment to aggregate shocks, and for the degree of real wage rigidity.

The total cost, in terms of the produced good, of creating $H(t)$ production units at $t$ is proportional to the leading productivity $A(t)$, and can be thought of in terms of foregone output. Because the distinction is important for the firm-worker bargaining problem, $C(H, U)$ is split into two components, investment $I(H)$ and search costs $S(H, U) H$ :

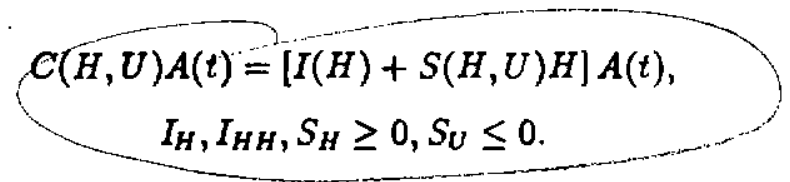

Investment includes capital investment and installation as well as training and organizational costs. $I(H)$ is increasing and (weakly) convex in $H$. Convexity captures the idea that it may be expensive to create fast, either at the aggregate or the individual level, and provides a motive for "smoothing" creation.

$S(H, U)$ is the flow search cost required to expect one hire per unit time, and is (weakly) increasing in aggregate hires $H$ and decreasing in aggregate unemployment $U$. It can be derived from a constant vacancy-posting cost and a matching function $H=H(U, V), H_{U}, H_{V}>0$, where $V$ denotes aggregate vacancies. ${ }^{7}$

Throughout the paper, we will be using the following functional form for creation

\footnotetext{
${ }^{6}$ Convexity at the aggregate level may be derived from a concave production function for capital. It may also be derived from linear individual adjustment costs but a non-degenerate distribution of polential entrants (e.g. heterogeneous observable skills), as in Diamond (1994). Convexity at the individual level may be derived from convex installation and training costs, assuming a fixed number of symmetric firms.

${ }^{7}$ Let $\pi>0$ denote the unit flow cost of posting a vacancy. If we invert the matching function and write it as $V=V(H, U)$, then the unit flow cost of hiring a worker is $S(H, U)=\pi V(H, U) / H$. The property $S_{H}>0$ requires that the matching function be less than unit-elastic with respect to $V$, which is a much weaker requirement than constant returns; the property $S_{U}<0$ only requires that the matching function be increasing in $U$.
} 
costs:

$$
\begin{aligned}
& I(H)=c_{0} H+\frac{1}{2} c_{1} H^{2}, \\
& S(H, U)=c_{2}\left(\frac{H}{U}\right)^{\frac{\eta}{1-\eta}}, \quad c_{0}, c_{1}, c_{2} \geq 0, \quad 0 \leq \eta<1 .
\end{aligned}
$$

The quadratic specification for $I(H)$ yields a simple linear form for the marginal investment cost. The search cost specification can be derived from the constant returns Cobb-Douglas matching function $H=\xi U^{\eta} V^{1-\eta}$. For notational simplicity, we henceforth denote the creation cost and its components by $C(t), I(t)$ and $S(t)$.

Consumer-Workers. We close the model by introducing consumer-workers in the simplest way possible. There are a continuum of infinitely-lived individuals indexed by $i \in[0, \bar{L}]$, each endowed with one unit of labor and shares over production units and the stock of non-produced goods. Individual $i$ 's intertemporal utility at time $t$ is given by

$$
\int_{i}^{\infty}\left[Q_{i}^{d}(s)+p(s) A(s) M_{i}^{d}(s)\right] e^{-r(s+1)} d s
$$

Utility is linear in both $Q_{i}^{d}(s)$ and $M_{i}^{d}(s), i$ 's consumption at $s$ of the produced and nonproduced goods. $^{8}$ Linearity greatly simplifies the consumer's side of the model, since it implies risk neutrality and gives a constant interest rate equal to the subjective discount rate $r$. We assume $r>\gamma$ to guarantee finite utility. $p(s)$ is the marginal utility of the non-produced good, normalized by the leading technology $A(s)$ (due, e.g., to technical progress in the utilization of the non-produced good). Using the produced good as a numeraire, $p(s)$ also represents the price (normalized by $A(s)$ ) of the non-produced good. Cyclical fluctuations in the price of intermediate inputs are introduced by assuming that $p(t)$ is an exogenous function of time.

A few aggregate relationships will be useful. The two goods market equilibrium conditions are:

\footnotetext{
It would have been very simple to add a linear lerm to account for a positive value of leisure. In the equilibrium conditions below, the marginal value of leisure would have enlered in exactly the same way as the price of the intermediate input. We chose to drop this term for simplicity.
} 


$$
\begin{gathered}
Q(t)=Q^{d}(t)+C(t) A(t), \\
\bar{M}=M^{d}(t)+E(t),
\end{gathered}
$$

where $Q^{d} \equiv \int_{i} Q_{i}^{d} d i, M^{d} \equiv \int_{i} M_{i}^{d} d i$, and, by fixed proportions, $E(t)$ is equal to the demand for intermediate inputs. Finally, aggregate unemployment is given by

$$
U(t) \equiv \bar{L}-E(t)
$$

\subsection{The Central Planner Problem}

We start by asking how a central planner would manage our economy, and derive the corresponding efficiency conditions. This analysis will help us characterize the efficient path of creative destruction, and will provide us with a benchmark for assessing the efficiency of the decentralized outcome.

Since utility is linear, the central planner always maximizes aggregate utility, whatever his distributional concerns may be. His problem is

$$
\max _{(H(t), \bar{a}(t))} \int_{0}^{\infty}\left[Q^{d}(t)+p(t) A(t) M^{d}(t)\right] e^{-r t} d t
$$

subject to (1), (2), (4)-(6), and the constraints $\bar{a}(t), H(t), U(t) \geq 0$, for all $t$, taking as given the path $\{p(t)\}_{t \geq 0}$ and the history $\{H(t)\}_{e<0}$ that determines the initial distribution of jobs. ${ }^{9}$ In this problem, the planner is assumed unable to improve the efficiency of matching in the labor market and takes the matching function and cost parameters as given.

The first order conditions with respect to $\bar{a}(t)$ and $H(t)$, respectively, are

$$
A(t-\bar{a}(t))-\left[p(t)+\tilde{w}^{E}(t)\right] A(t)=0,
$$

\footnotetext{
${ }^{9}$ The constraint $U(t) \leq \bar{L}$ need not be imposed explicitly because it is guaranteed by $H(t) \geq 0$.
} 


$$
\tilde{c}^{E}(t) A(t)=\int_{1}^{t+T(t)}[A(t)-A(s-\tilde{a}(s))] e^{-(r+\delta)(s-t)} d s
$$

where

$$
\tilde{w}^{E}(t)=-C_{U}(t)+\mu(t), \quad \mu(t) \geq 0 \text { with }^{\mu}={ }^{n} \text { if } U(t)>0,
$$

and

$$
\tilde{c}^{E}(t)=C_{H}(t)
$$

The marginal cost variables $\tilde{w}^{E}(t)$ and $\tilde{c}^{E}(t)$ play an important role in the comparison of the centrally planned with the decentralized outcome (the superscript $E$ stands for "Efficient"). They designate, respectively, the "shadow" wage of a worker and the marginal creation cost of a job, normalized by $A(t)$. Equation (7) is an exit condition that requires the quasi-rents from a job to be zero at the time of destruction: $A(t-\bar{a}(t))$ is the output of a production unit that has reached the exit age $\bar{a}(t)$ and $\left[p(t)+\tilde{w}^{E}(t)\right] A(t)$ is its operating cost, equal to the cost of the unit of intermediate input and of labor used. Equation (8) is an entry condition that equates the marginal creation $\cos t \tilde{c}^{E}(t) A(t)$ of a job created at $t$ to the expected present value of quasi-rents over its planned lifetime $T(t)(A(t)$ being the job's output and, by (7), $A(s-\bar{a}(s))$ its operating cost at $s)$.

The shadow wage $\tilde{w}^{E}(t)$ is equal to the reduction $-C_{U}(t)$ in total search costs that would result were the worker to remain unemployed, plus the constraint multiplier $\mu(t)$. If the constraint $U(t) \geq 0$ is not binding, the multiplier is zero and the "shadow" wage is $-C_{U}(t)$; if it is binding, the shadow wage is higher, equal to the value needed in (7) to reach full employment.

The only beneficial function unemployment plays in this efficient economy is to reduce the search costs of creation. Note that if $\lim _{U \rightarrow 0} C_{U}=\infty$ (which is the case with functional form (3) when $c_{2}>0$ ), then there is always a small enough positive value of $U$ that satisfies (7), so it is always efficient to have some unemployment. If, on the other hand, $C_{U} \equiv 0$ and unemployment does not facilitate the creation process (which is the case when $c_{2}=0$ ), then we have full employment $U=0$ as long as $p(t)$ is sinall enough to 
guarantee a minimum of profitability.

An equilibrium for the centrally planned economy is a path $\{\bar{a}(t), H(t), U(t)\}_{i \geq 0}$ that satisfies the exit and entry equations (7)-(10) and

$$
\begin{gathered}
\bar{a}(t)=T(t-\bar{a}(t)), \\
U(t)=\tau-\int_{0}^{\bar{\sigma}(t)} H(t-a) e^{-\delta a} d a,
\end{gathered}
$$

given a history $\{H(t)\}_{t<0}$ that determines the initial distribution of jobs. Equation (11) gives the function $T(t)$ implicitly as a transformation of $\vec{a}(t)$, which holds as long as destruction is always taking place. It states that the age $\bar{a}(t)$ of the oldest job at $t$ is equal to the maximum lifetime $T$ that was planned for it at its time of creation $t-\bar{a}(t)$. Equation (12) gives unemployment as a function of the history of hiring, and follows immediately from (1) and (6).

\subsection{Decentralized Bargaining Equilibrium}

We now turn to the determination of equilibrium in the economy when the labor market is governed by decentralized bargaining and the goods market may be subject to a profitability distortion.

The Bargaining Situation. Abstracting away from internal labor markets and onthe-job search, we assume that all workers in new production units are hired from the unemployment pool and all workers from destroyed production units return there. Firms can freely enter the labor market at any time to create jobs. To create a job at time $t$, a firm searches for a worker at the flow cost $S(t)$ described above. The match between worker and firm creates a surplus $\Pi(t)$ that must be bargained over. Assuming generalized Nash bargaining, a share $\beta \in] 0,1[$ of the surplus goes to the worker and $(1-\beta)$ goes to the firm.

The way the worker receives payment for his share over time is indeterminate, as 
long as the present value at $t$ of the payments is $\beta \Pi(t)$. One assumption could be that all payments to the worker are made at $t$, and that a contract is signed that fixes the planned maximum duration of employment to $T(t)$, the value that maximizes the surplus from the match. Alternatively, if such a contract is not enforceable, we could assume a payment flow consistent with continuous Nash bargaining over the remaining surplus. In this case, one can show that the surplus reaches zero and separation takes place after the same maximum duration $T(t)$. Except for the time pattern of wage payments, both assumptions are equivalent.

An important issue in calculating the surplus $\Pi(t)$ is the way creation costs are taken into account. The surplus from a match is the value it creates above the firm's and worker's best alternatives. Thus, all search costs and match-specific setup costs incurred before bargaining are "sunk" and cannot be subtracted in calculating the surplus. Moreover, even if match-specific setup costs are incurred after bargaining, there may not be a way to get the worker to post a "bond" that would prevent him from renegotiating his position after those costs are incurred. ${ }^{10}$ To capture this distinction, we introduce a parameter $\phi \in[0,1]$ that measures the share of setup costs that are match-specific and cannot be bonded away, and are therefore "sunk" for the firm. The two parameters $\phi$ and $\beta$ measure the relative bargaining power of workers over firms, $\phi$ strengthening the worker's threat point and $\beta$ increasing the share he gets of the surplus.

Business $C y c l e s$. The distortion to profit margins is introduced as a flow subsidy $z(t) A(t)$ (or a $\operatorname{tax}$, if it is negative) the government pays to each production unit in operation, and finances through a lump-sum tax on households. As we mentioned in the introduction, this goods-market distortion can be loosely thought of as a device that captures the effect of aggregate demand on profit margins. From this perspective, cyclical fluctuations in $z(t)$ will have a similar effect to fluctuations in intermediate input prices $p(t)$. Those two variables enter the profit margin in parallel, and will sometimes be

\footnotetext{
${ }^{10}$ For a discussion of "bonding" issues in the context of the effieiency wage literature, see Katz (1987). For an exposition of Nash bargaining in the presence of specific investment, see Grout (1984).
} 
grouped into a single "business cyclen variable:

$$
b(t) \equiv z(t)-p(t)
$$

Throughout the paper, we assume that the path $\{b(t)\}_{t \geq 0}$ is continuous and such that positive creation and destruction are taking place at all points in time. Because our main results do not depend on uncertainty, we assume that the path of $b(t)$ is known with certainty.

Equilibrium Conditions. Appendix A.1 derives the equations governing the equilibrium bargaining situation described above. Given a history $\{H(t)\}_{t<0}$ that determines the initial distribution of jobs, an equilibrium for this economy is a path $\{\bar{a}(t), H(t), U(t)\}_{t \geq 0}$ that satisfies the system of equations

$$
\begin{gathered}
A(t-\bar{a}(t))-\left[\tilde{w}^{D}(t)-b(t)\right] A(t)=0, \\
\tilde{c}^{D}(t) A(t)=\int_{t}^{t+T(t)}[A(t)-A(s-\bar{a}(s))] e^{-(r+\delta)(a-t)} d s,
\end{gathered}
$$

where

$$
\tilde{w}^{D}(t)=\frac{H(t)}{U(t)} \frac{\beta}{1-\beta}\left[\phi I_{H}(t)+S(t)\right]
$$

and

$$
\tilde{c}^{D}(t)=\left(1+\frac{\beta}{1-\beta} \phi\right) I_{H}(t)+\frac{1}{1-\beta} S(t),
$$

as well as equations (11)-(12) that define $T(t)$ and $U(t)$.

The decentralized equilibrium conditions (14)-(17) have the sane structure as the first-order conditions (7)-(10) of the central planner problem, except that cost signals may be distorted. The exit condition (7) states that the marginal profitability of an exiting job should be zero, but now the "shadow" wage $\tilde{w}^{D}(t) A(t)$ (the superscript $D$ stands for "Decentralized") and profit margins (through $z(t)$ ) may be distorted. Similarly, in the free-entry condition (8), the "effectiven creation cost $\tilde{c}^{D}(t) A(t)-$ defined as the 
marginal cost that is effectively being set equal to the present value of a production unit - is in general distorted.

Both cost signals depend on the relative bargaining positions of workers and firms. The shadow wage $\tilde{w}^{D}(t) A(t)$ represents the opportunity cost to a worker of remaining on the job rather than turning unemployed and searching for another job. It is equal to the instantaneous probability $H(t) / U(t)$ of finding another match times the part $\beta \Pi$ of the surplus he would get there. By the free-entry condition, the latter turns out to depend on the unbonded match-specific creation cost, and is naturally increasing (in partial equilibrium) with the worker bargaining power parameters $\phi$ and $\beta$. It is important to keep in mind that $\tilde{w}^{D}(t) A(t)$ measures an opportunity cost, and not the actual flow of wage payments received by employed workers. ${ }^{11}$

The effective creation cost $\tilde{c}^{D}(t) A(t)$ is also increasing (in partial equilibrium) with worker bargaining power $\phi$ and $\beta$. Intuitively, if firms lose a large share of the match surplus to workers, their incentive to enter will be reduced and they will act as if they faced an effectively higher entry cost.

The Nature of Unemployment. Equilibrium in this economy generally involves positive unemployment, whose nature is intimately tied the bargaining situation between workers and firms. If there were no unemployment, workers would find it infinitely easy to find an alternative job. Their outside alternative of moving continuously from job to job to capture their share of the match surpluses would make their shadow wage $\tilde{w}^{D}$ infinite (equation 16). That would deter any job creation, which is inconsistent with full employment. Unemployment thus acts as an equilibrium "discipline device" to limit the bargaining power of workers and preserve firm profitability. ${ }^{12}$

Looking at equation (16), there is always a positive unemployment level $U$ that gives the shadow wage $\tilde{w}^{D}$ in (14), as long as $\phi I_{H}+S>0$. This last quantity measures the

\footnotetext{
"Under continuous Nash bargaining, it is equal to the actual wage paid at firms that have reached the scrapping age $\bar{a}(t)$.

${ }^{12}$ Unemployment plays a similar role as a discipline device in some efficiency wage models (e.g. Shapiro and Stiglitz 1984).
} 
match-specific creation costs that cannot be bonded away, equal to unbonded specific investment plus search costs. It is those match-specific expenditures that in equilibrium lead to the creation of a match surplus, and are equal to the firm's share of this surplus under free entry. As we will see later, whether it is specific investment or search costs that are the primary cause of the match surplus and unemployment can lead to important differences in aggregate behavior. ${ }^{13}$ Note that the economy can exhibit positive unemployment due to specific investment $\phi I_{H}>0$, even if search costs are zero $\left(c_{2}=0\right)$ and the centrally planned outcome requires full employment. Naturally if $\phi I_{H}+S=0$, the match surplus is zero and no unemployment is needed to discipline workers. In this case the economy will be in full employment, as long as $b(t)$ is small enough to guarantee a minimum of profitability - which we always assume.

\subsection{Efficiency of the Decentralized Equilibrium}

Cost signals in the decentralized economy are in general distorted, and the outcome will not generally be efficient. However, there are conditions on the economy's parameters under which the decentralized outcome will be socially efficient. Those conditions provide us with a very useful benchmark for analyzing market inefficiencies.

Clearly, the first condition is that the profit margin distortion $z(t)$ be zero. In this case, one can show that the following configuration for the bargaining parameters guarantees that $\tilde{w}^{D}=\tilde{w}^{E}$ and $\tilde{c}^{D}=\tilde{c}^{E}$, and thus that the decentralized outcome is efficient: ${ }^{14}$

$$
(\phi, \beta)=(0, \eta)
$$

Full bonding $\phi=0$ ensures that firms recover all of their investment $I_{H}(t)$. Efficiency requires giving this extreme bargaining position to firms because we have assumed that all

\footnotetext{
${ }^{13}$ A good synthesis of the literature on the second type of unemployment based on search costs can be found in Pissarides (1990).

${ }^{14}$ Hosios (1990) discusses the efficiency condition in decentralized bargaining models based on search coste. In general, this efficiency condition only exists if the matching function exhibits constant returns.
} 
investment is done by them. The condition $\beta=\eta$ on the share parameter helps equate the private and social marginal costs of search, which are in general different because of the well known "congestion" and "thick-market" externalities captured by the two arguments in the function $S(H, U) .^{15}$

\section{Creation, Destruction, and Unemployment: Tim- ing and Volatility}

In this section we focus on cyclical aspects of creative destruction. We contrast the cyclical response of an efficient economy with an inefficient economy in terms of observable characteristics of timing and volatility of creation, destruction and unemployment. ${ }^{16}$

\subsection{Efficient Restructuring over the Cycle}

We start by considering the response of an efficient economy, where $(\phi, \beta)=(0, \eta)$, to business cycle fluctuations in $b(t)$. To be consistent we assume all fluctuations in $b(t)$ are due to real fluctuations in intermediate input prices $p(t)$, but a decentralized economy with the same bargaining parameters would behave exactly the same in response to an (inefficient) demand distortion $z(t)$,

A basic but fundamental feature of the efficient economy is that the only role of unemployment is to facilitate labor reallocation. Thus, if job creation entails only investment but no search costs $\left(c_{2}=0\right)$, efficient equilibrium unemployment is zero. Aggregate

\footnotetext{
${ }^{15}$ Those two externalities operate as follows: $A$ decision to create a job and search for a worker makes search costlier for others $\left(S_{H} \geq 0\right)$; a decision to destroy a job and add a worker to the unemployment pool makes search cheaper for others $\left(S_{U} \leq 0\right)$.

${ }^{16}$ The distinction between efficient and inefficient economies is starker when lejsure unemployment is not an important source of employment fluctuations. Those are precisely the circumstances we wanted to stress by assuming in section 2.3 that $b(t)$ is always low enough to warrant a shadow wage above the value of leisure (set to zero for simplicity). For an analysis of gross flows stressing the role of leisure in employment fluctuations, see Davis and Haltiwanger (1990).
} 
shocks are entirely absorbed by fluctuations in the shadow wage, while all quantities including labor market flows and stocks remain unaffected.

The introduction of search costs gives rise to unemployment, whose role is to facilitate reallocation. Figure 1 simulates the path of such an efficient economy, with positive search costs and linear investment costs $\left(c_{0}, c_{2}>0\right.$ and $\left.c_{1}=0\right)$. Business cycles are generated by a deterministic sine-wave in $b(t) .^{17}$ Panel (a) shows one full business cycle in $b(t)$, with its trough in the middle of the diagram. Panels (b)-(d) present the path of output, creation and destruction, and unemployment. ${ }^{18}$

The dynamics of those variables are driven by the fact that the opportunity cost of creating unemployment is lowest at the bottom of a recession, when production is least profitable. Given that unemployment is needed to facilitate reallocation, it is efficient to concentrate this process around the trough of the recession. ${ }^{19}$ Recessions are thus characterized by a sharp increase in destruction that spills workers into the unemployment. pool, followed promptly by a large spurt of creation, which reaches its peak at the same time as unemployment. Creation, destruction and unemployment are tightly coordinated and positively correlated, although with a slight job destruction lead to let unemployment accumulate. Furthermore, there is a motive to concentrate the reallocation process sharply around the recession's trough. Consequently, despite the symmetry of the driving force, the economy's observed cyclical response is asymmetric. Recessions and recoveries are sharp and short-lived, while expansions are prolonged and fade away slowly before the onset of the next recession.

The extreme synchronization of the reallocation process is a distinctive feature of an

\footnotetext{
${ }^{17}$ The figure was generated with the following parameters: $r=0.065, \gamma=0.028, \delta=0.05, \eta=0.5$ and $T=1$. Creation cost parameters are $c_{0}=0.0790, c_{1}=0$ and $c_{2}=0.045$. The economy is efficient with bargaining parameters $\beta=\eta$ and $\phi=0 . b(t)$ follows a sine-wave of period 4 years, mean 0.321 , and smplitude \pm 0.044 . The simulation method used is the same as in Caballero and Hammour (1994).

"What may appear as "irregularities" in some of the figures are in fact the result of the "echo" effect of previous cycles on the age-distribution of jobs at the start of the current cycle.

${ }^{10}$ This point is emphasized by Davis (1987) and Davis-Haltiwanger (1990). The literature contains several similar "opportunity cost" models of different types of investment activities during recessions e.g., Ball (1991), Aghion and Saint-Paul (1992), Gali and Hammour (1992).
} 
1.a: Aggregate Shock

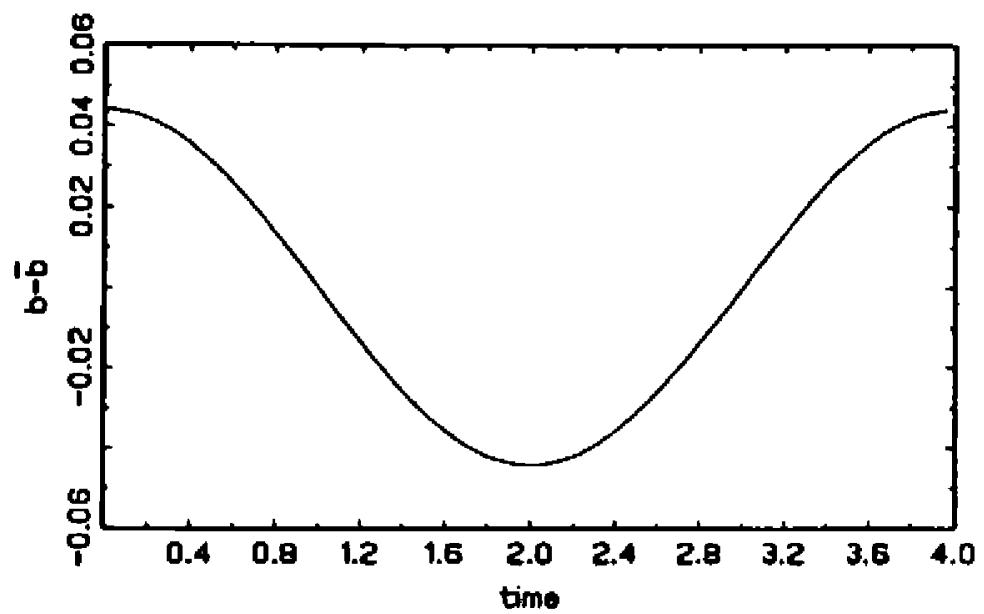

1.b: Gross Output [Detrended]

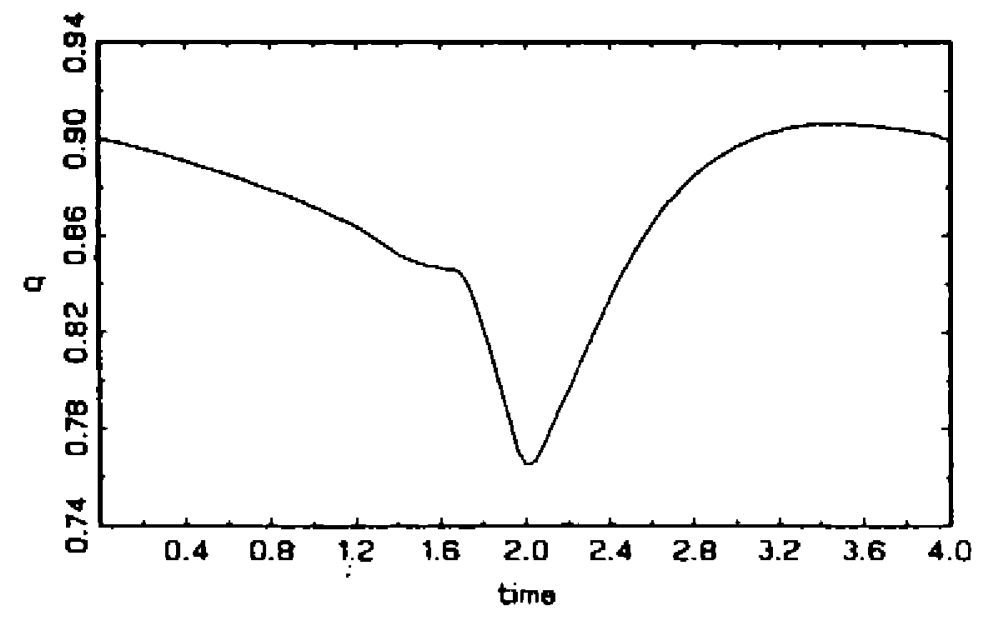

1.c: Creation and Destruction

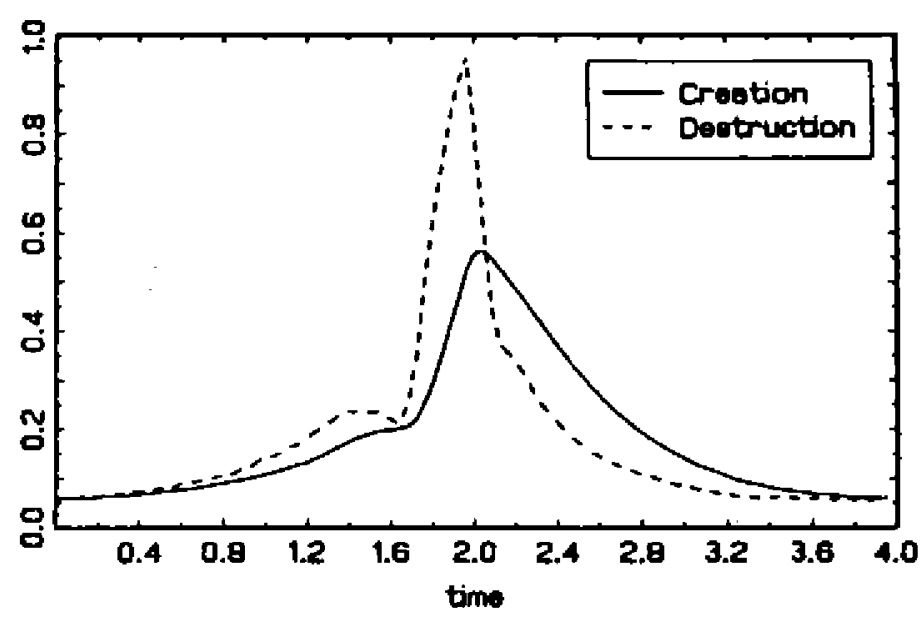

1.d: Unemployment

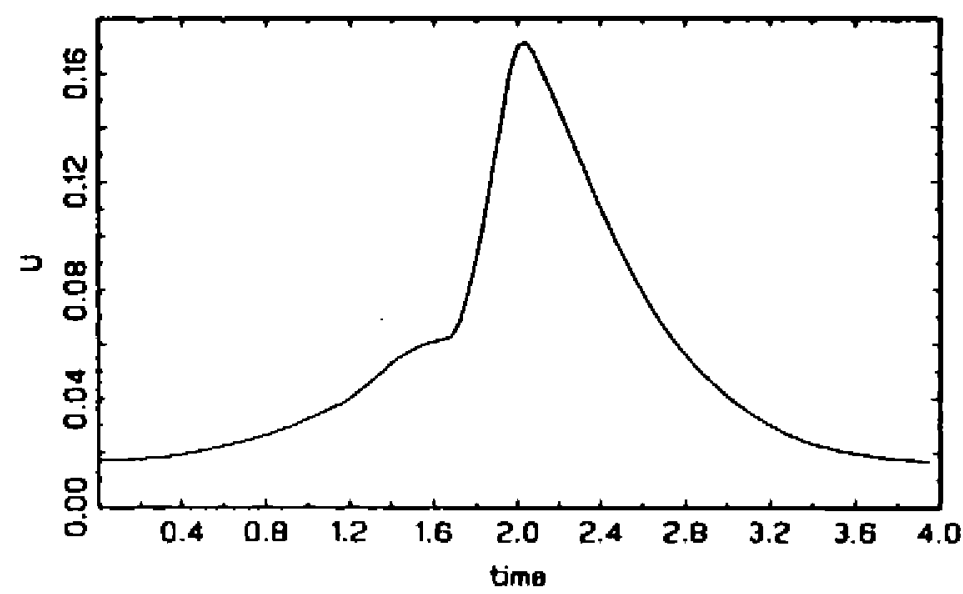


efficient economy with significant search costs, where sharp recessions are a preparation for strong recoveries. An efficient decentralized economy supports this equilibrium with a shadow wage that does not accommodate aggregate shocks one for one. This occurs because unemployment facilitates creation, and the latter, by increasing the demand for new hires, counteracts the direct downward pressures on the wage of an exogenous squeeze in profit margins.

The incentive to concentrate reallocation near at the bottom of a recession may be counteracted by an incentive to smooth the creation process. If marginal investment costs are now increasing $\left(c_{1}>0\right)$, creation must be smoothed, as it becomes expensive to vary the intensity of creation over the cycle. Figure 2 presents the path of creation and destruction in an efficient economy with both increasing marginal investment and search costs $\left(c_{0}, c_{1}, c_{2}>0\right) .{ }^{20}$ Since the only purpose of destruction and unemployment in the efficient economy is subsequent creation, destruction and unemployment remain synchronized with creation, and are therefore also smoothed. This strong joint-smoothing behavior is another aspect of the coupling of creation and destruction in an efficient economy.

\subsection{Inefficient Restructuring: Timing and Volatility}

The dynamics of creation, destruction and unemployment in the efficient economy is fundamentally determined by the usefulness of unemployment for worker reallocation. If the decentralized outcome does not happen to be efficient, the creation-cost saving signals driving unemployment may be distorted. More dramatically, the timing of creation and destruction may be disrupted and the two processes may be completely decoupled. We discuss those two aspects of inefficient restructuring in turn.

\footnotetext{
${ }^{20}$ The figure was generated with the same parameters as figure 1 , except that the creation cost parameters are now $c_{0}=0.0790, c_{1}=0.75$ and $c_{2}=0.0113$; and the $b(t)$ wave is of mean 0.422 and amplitude \pm 0.064 .
} 
Figure 2: Efficient Joint-Smoothing of Creation and Destruction

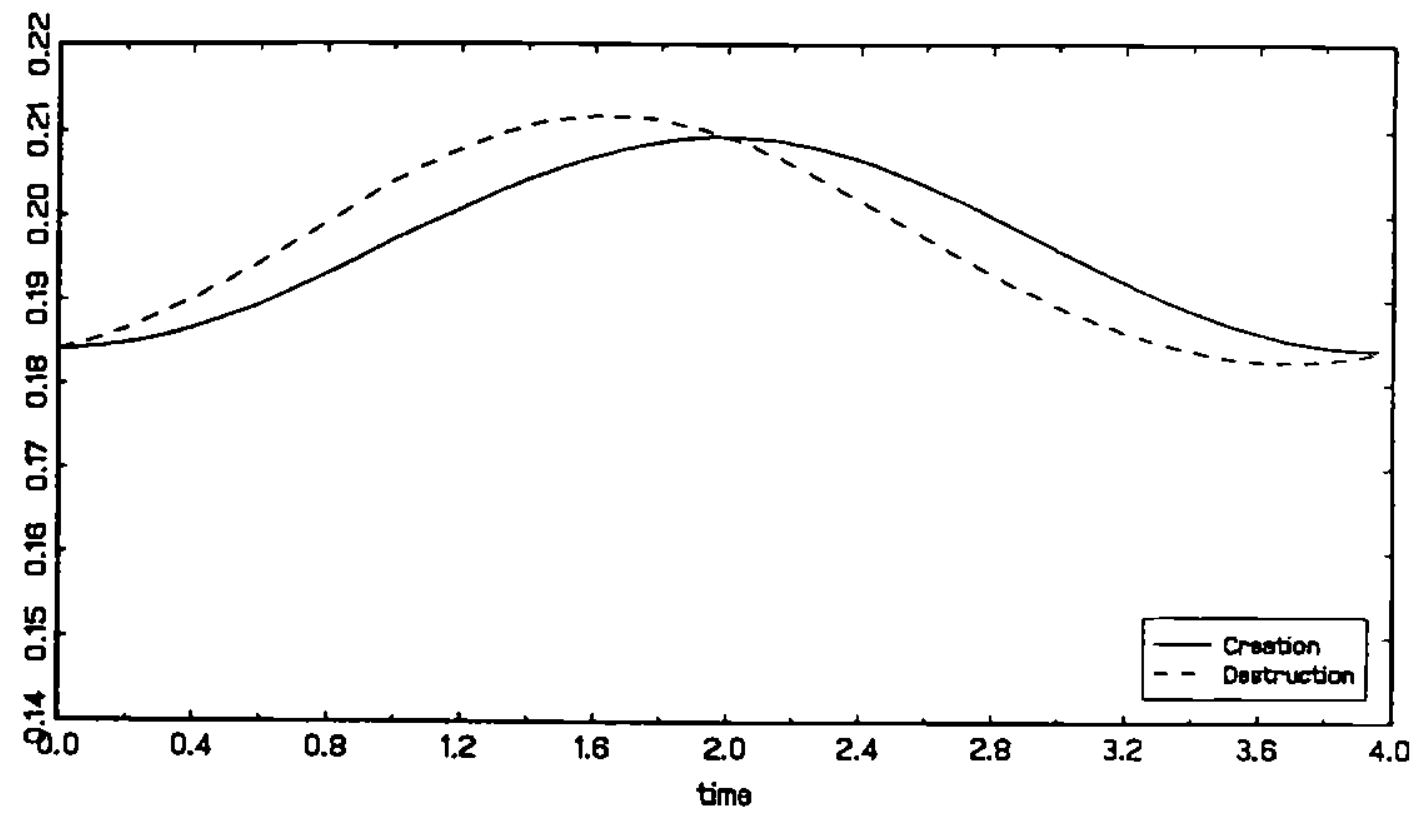


Distorted Reallocation Incentives. As we have seen, an efficient economy concentrates reallocation during recessions, when the opportunity cost of generating the necessary unemployment is lowest. The same intertemporal substitution incentives are also present in an inefficient economy with significant search costs, but the extent to which restructuring is concentrated in recessions may be out of line.

To see this point most clearly, we consider the same economy as in figure $1\left(c_{0}, c_{2}>0\right.$ and $\left.c_{1}=0\right)$, but now introduce inefficiency in the form of $\beta \neq \eta$ ( $\phi$ remains zero). Figure 3 shows creation (panel a) and destruction (panel b) for two economies that are identical except for their different values of $\beta^{21}$ It is clear that a higher $\beta$ reduces intertemporal substitution incentives. In such an economy, the presence of strong workers $(\beta>\eta)$ will tend to muffle fluctuations in profit margins, and the economy will restructure less than efficiently during recessions; weak workers $(\beta<\eta)$ will lead to the opposite, and the economy will restructure excessively during recessions.

Decoupling of Creation and Destruction. Distorted volatility results from models of decentralized bargaining based on search costs. But whether the economy's cyclical response is muted or amplified, creation and destruction remain tightly synchronized and recessions remain a time of intense restructuring. New and potentially important effects can result from the introduction of specific investment with imperfect bonding. Imperfect bonding can derail the reallocation process over the cycle and decouple creation and destruction, both in terms of synchronization and joint-smoothing. Recessions become a time of wasteful unemployment, unassociated with greater reallocation activity.

The decoupling of creation and destruction is most clearly analyzed by temporarily setting search costs to zero, so unemployment plays no role in facilitating reallocation. Much of what happens in this case to the cyclical pattem of creation and destruction is driven by "rigidity" in the shadow wage $\tilde{w}^{D}(t)$. Recall that, when $c_{2}=0$, the shadow wage in the efficient economy $(\phi=0$ or $\beta=0$ ) absorbs one-to-one all fluctuations in $b(t)$.

\footnotetext{
${ }^{21}$ The figure was generated with the same parameters as figure 1, except that $\beta$ now takes two values: 0.2 or 0.5 .
} 


\section{3.a: Creation}

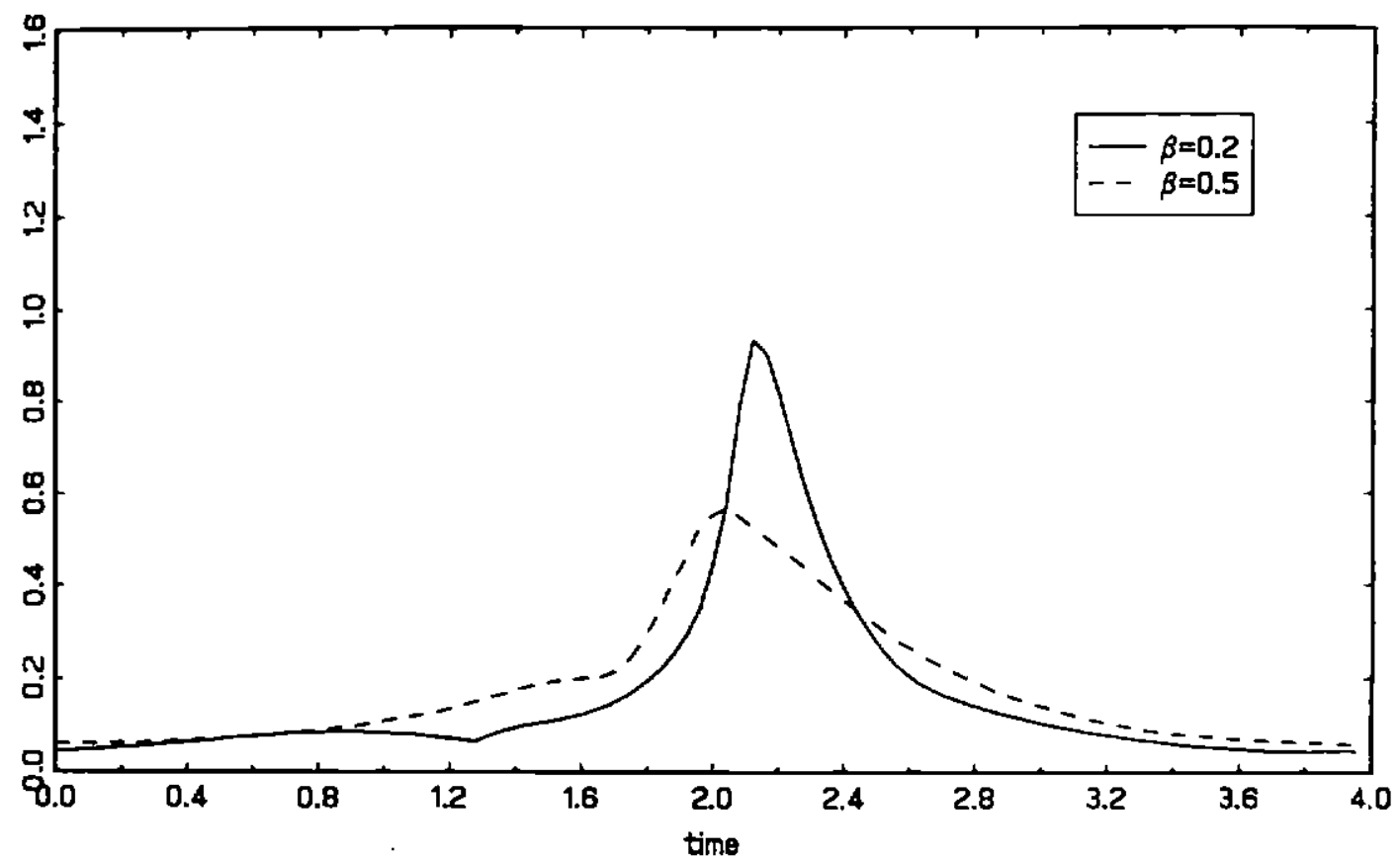

3.b: Destruction

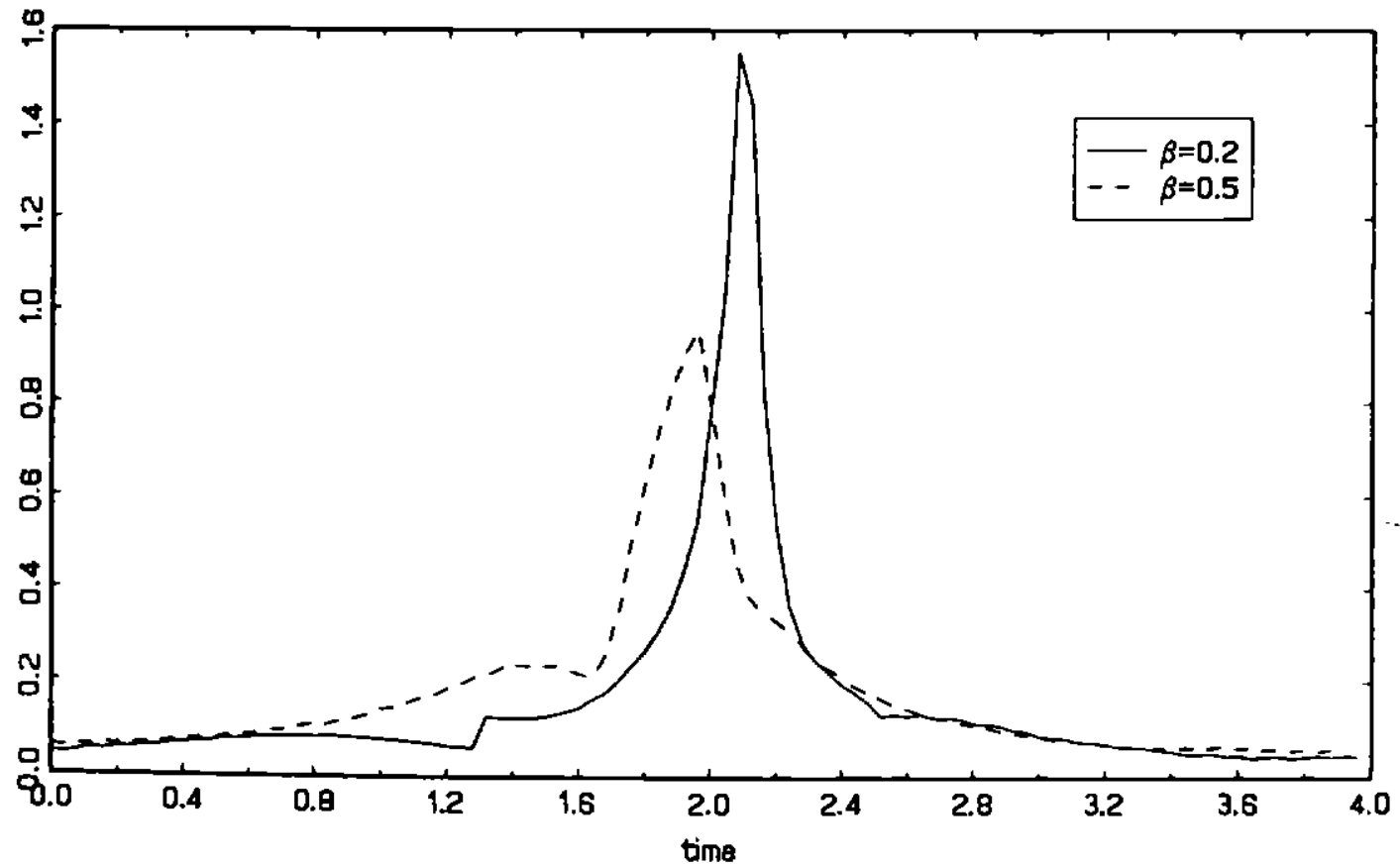


The economy exhibits no unemployment and no quantity responses to cycle. If workers have oome bargaining power $(\phi, \beta>0)$, the economy becomes inefficient and generates positive unemployment. Not only may the wage only partly offset movements in $b(t)$, but whatever part of the change in $b(t)$ it does offset will also require quantity movements in unemployment and hiring to bring the wage to its new equilibrium (see equation 16). The first type of shadow wage rigidity we call overt rigidity, and the second type covert rigidity.

Creation-Driven Recessions. The form of wage rigidity affects the nat ure of recessions, whether they are principally time of depressed hiring or times of intense destruction and cleansing of the productive structure. An interesting feature of our economy is that the nature of wage rigidity is determined by the - apparently unrelated - structure of creation costs. Most inefficient parameter configurations involve both types of rigidity, but in the extreme case where marginal investment costs are constant $\left(c_{1}=0\right)$, the economy exhibits a pure form of covert rigidity. In this case, recessions are entirely creation-driven.

To see this note that constant marginal creation costs implies that the free-entry condition (15), together with the definition of $T(t)$ in (11), is solved for a constant scrapping age $\bar{a}^{*}$. But the latter can occur only if the profitability (14) of exiting $\bar{a}^{*}$-year old jobs remains unchanged over the cycle, which requires that the wage fully absorb fluctuations in $b(t)$. Although the wage falls in a recession by the same amount as in an efficient economy, covertly it is rigid because this drop requires by (16) a fall in the hiring intensity $H(t) / U(t)$ - i.e. a fall in hiring and/or a rise in unemployment.

The economy exhibits in this case a perfect "insulation" mechanism similar to that discussed in Caballero and Hammour (1994), by which the fall in creation in response to a negative profitability shock leads to a fall in shadow wages that insulates the profitability of existing jobs. ${ }^{22}$ Recessions are completely driven by a fall in creation, while the

\footnotetext{
${ }^{22}$ In Caballero and Hammour (1994) we model an industry in isolation facing an exogenous consumption wage and downward-sloping demand. Insulation operates through the goods rather than the labor market,
} 
scrapping age on the destruction margin does not respond. ${ }^{23}$ This leads to a breakdown in efficiency and a complete decoupling of creation and destruction. Higher unemployment in recessions is wasteful, since the economy takes no advantage of it to intensify the reallocation process. On the contrary, the rise in unemployment here is caused by a fall in job creation, and the two are negatively correlated.

Destruction-Driven Recessions. Perfect insulation occurs in the extreme case where marginal investment costs are constant. If investment costs are increasing $\left(c_{1}>0\right)$, there is an incentive to smooth creation over the cycle. This dampens the cyclical response of creation and its effect on $H(t)$ and $U(t)$, and therefore limits the extent to which wages can fall to accommodate a negative profitability shock and insulate existing production units. The shadow wage exhibits in this case a degree of overt rigidity. By the exit condition (14), this means that the scrapping age $\bar{a}(t)$ must fall and the rate of destruction must rise to accommodate part of the aggregate shock. To the extent this happens, recessions are destruction- rather than creation-driven, and lead to a cleansing of outdated production units.

Figure 4 presents an example of the phenomenon discussed above, when aggregate investment costs are convex $\left(c_{0}, c_{1}>0\right)$ and there are no search costs. ${ }^{24}$ The business cycle variable $b(t)$ in panel (a) is similar to that in figure 1 . In sharp contrast with the efficient cycle in figure 1, creation and destruction are decoupled and are now negatively correlated (panel c). The stark difference between the efficient and inefficient cycles in figures 1 and 4 can seen in figure 5, which displays the corresponding Beveridge curves. ${ }^{25}$ The upper panel reveals the strong synchronizing incentives of unemployment acting as a

\footnotetext{
via movements along the demand curve.

${ }^{23}$ This does not mean that the rate of job destruction remains constant over time. Despite the constant scrapping age, destruction will vary as a result of the "echo" effect of past cyclical variations in hiring on the current age distribution of jobs.

${ }^{24}$ The figure was generated with the same parameters as figure 1 , except that the economy is now inefficient with $\phi=1$ and $\beta=0.5$; the creation cost parameters are $c_{0}=0.0790, c_{1}=1.00$ and $c_{2}=0$; and the $b(t)$ wave is of mean 0.456 and amplitude \pm 0.071 .

${ }^{25}$ The free shif-parameter $\xi$ in the matching function (see section 2.1 ) was chosen arbitrarily to gencrate this figure.
} 
4.a: Aggregate Shock

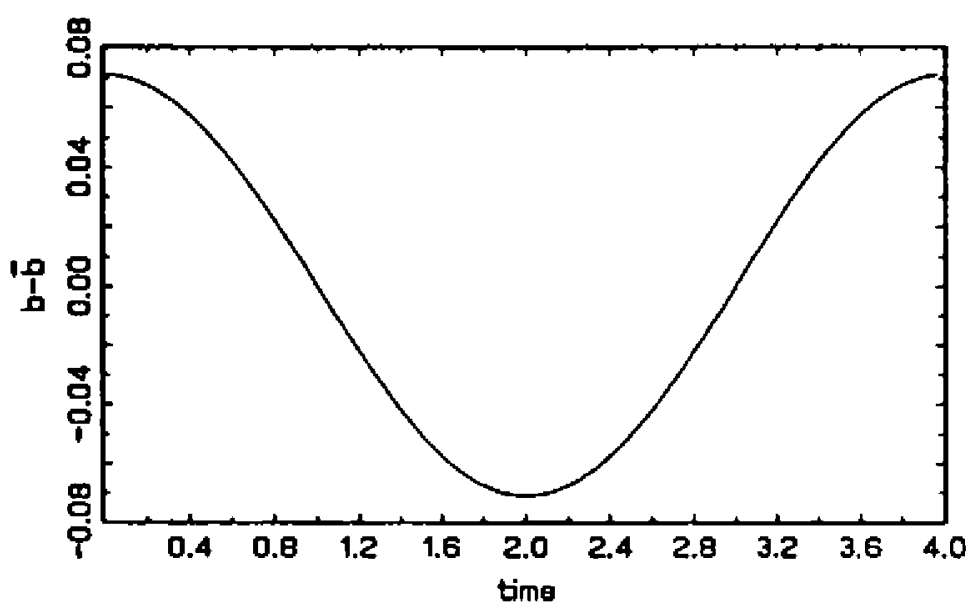

4.b: Gross Output [Detrended]

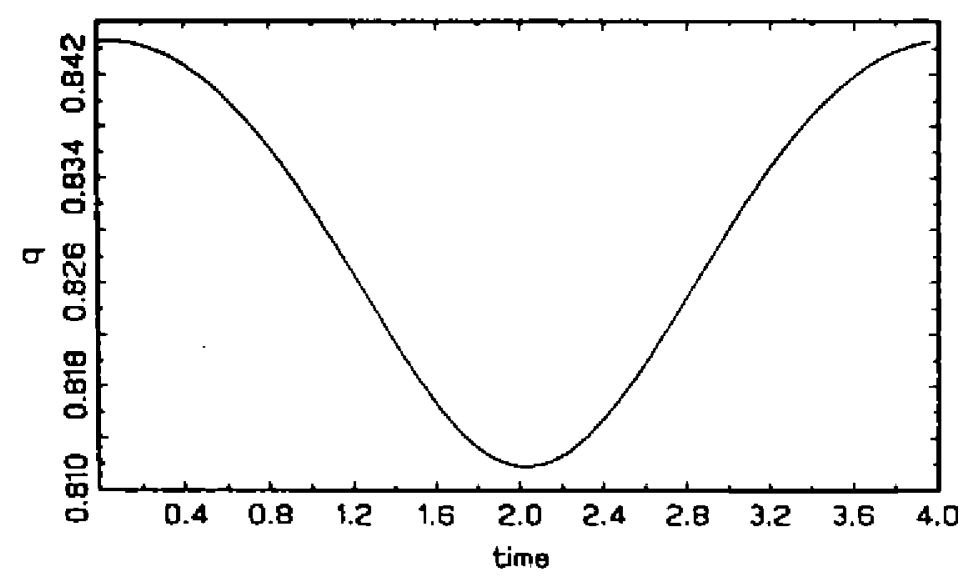

4.c: Creation and Destruction

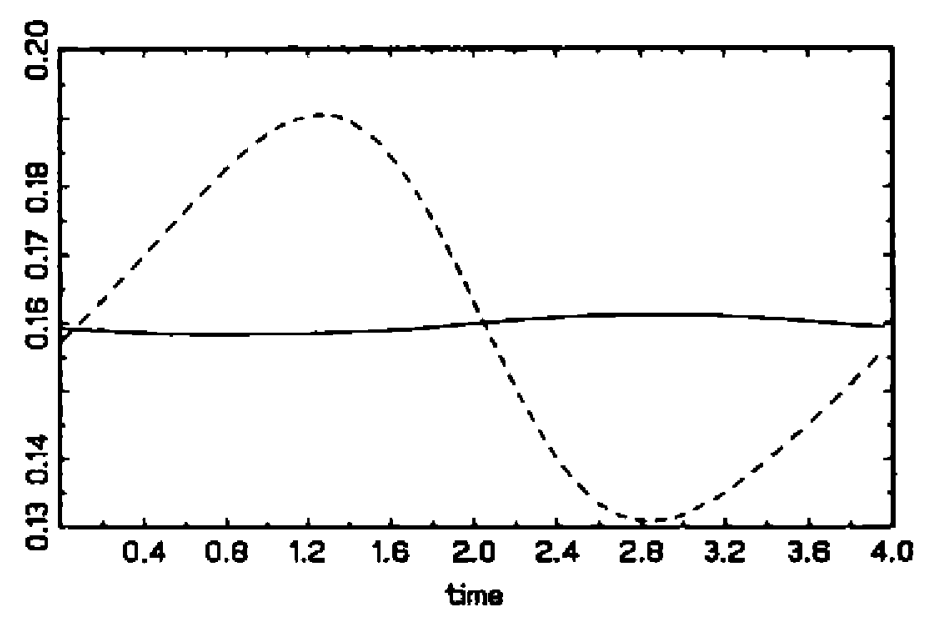

4.d: Unemployment

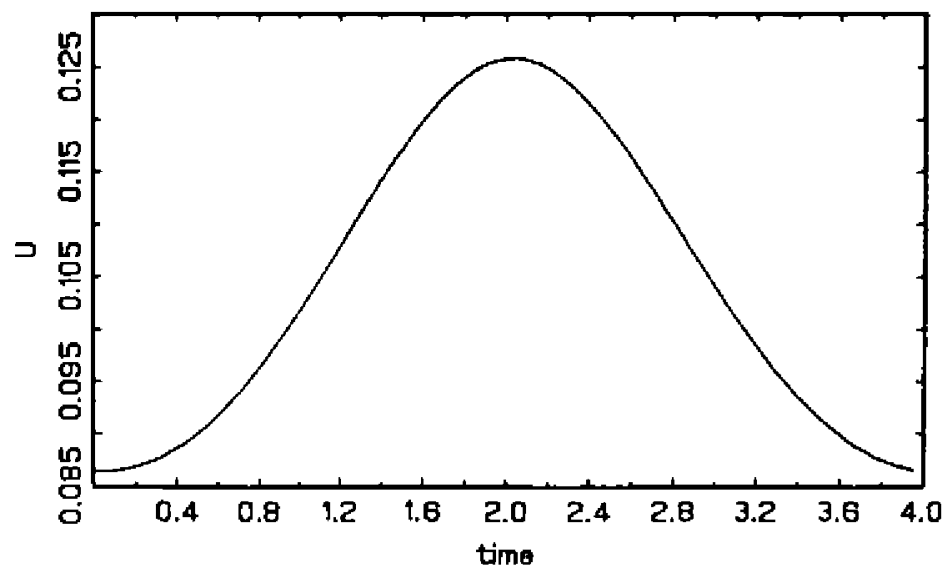


5.a: Efficient Economy

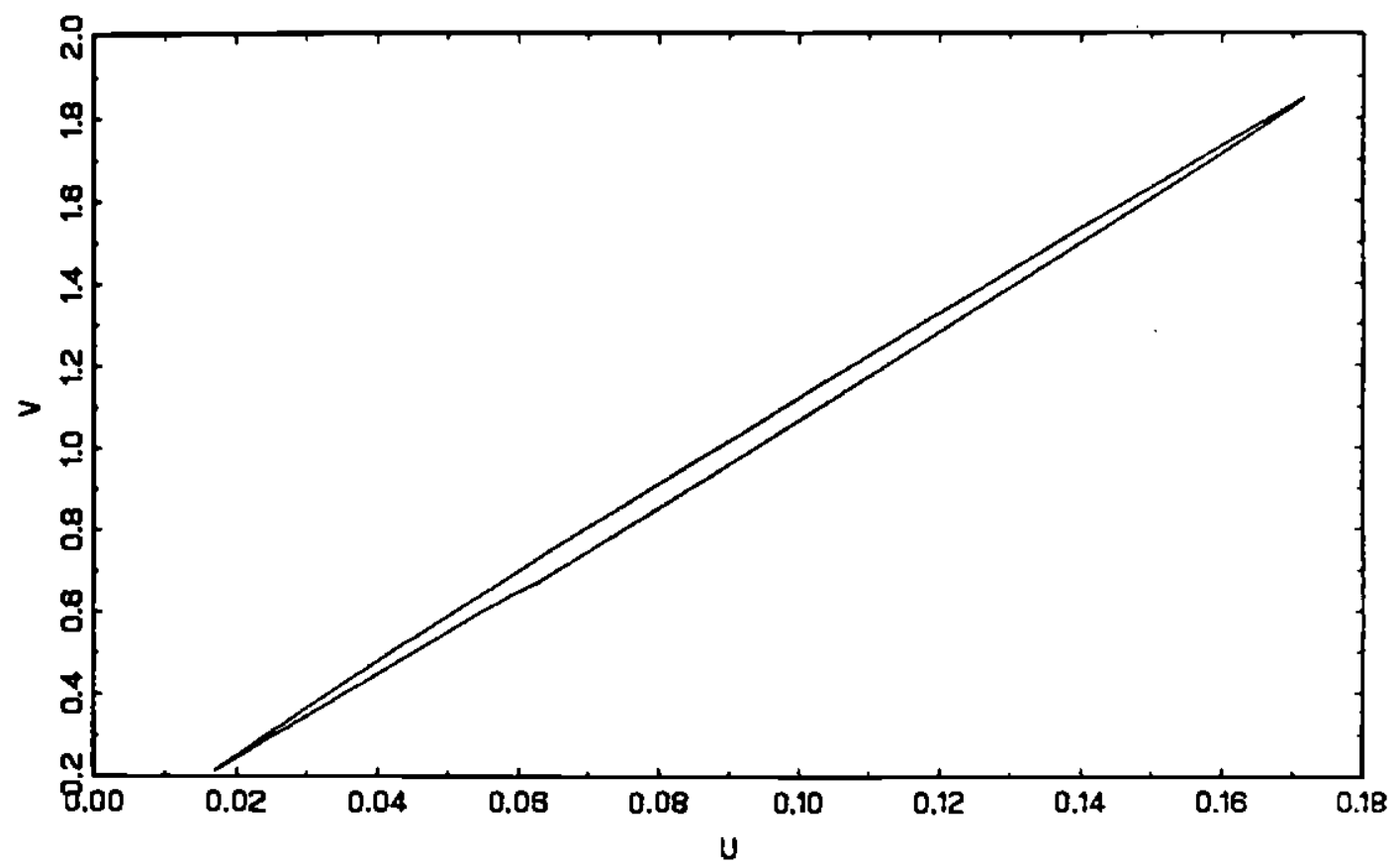

5.b: Inefficient Economy

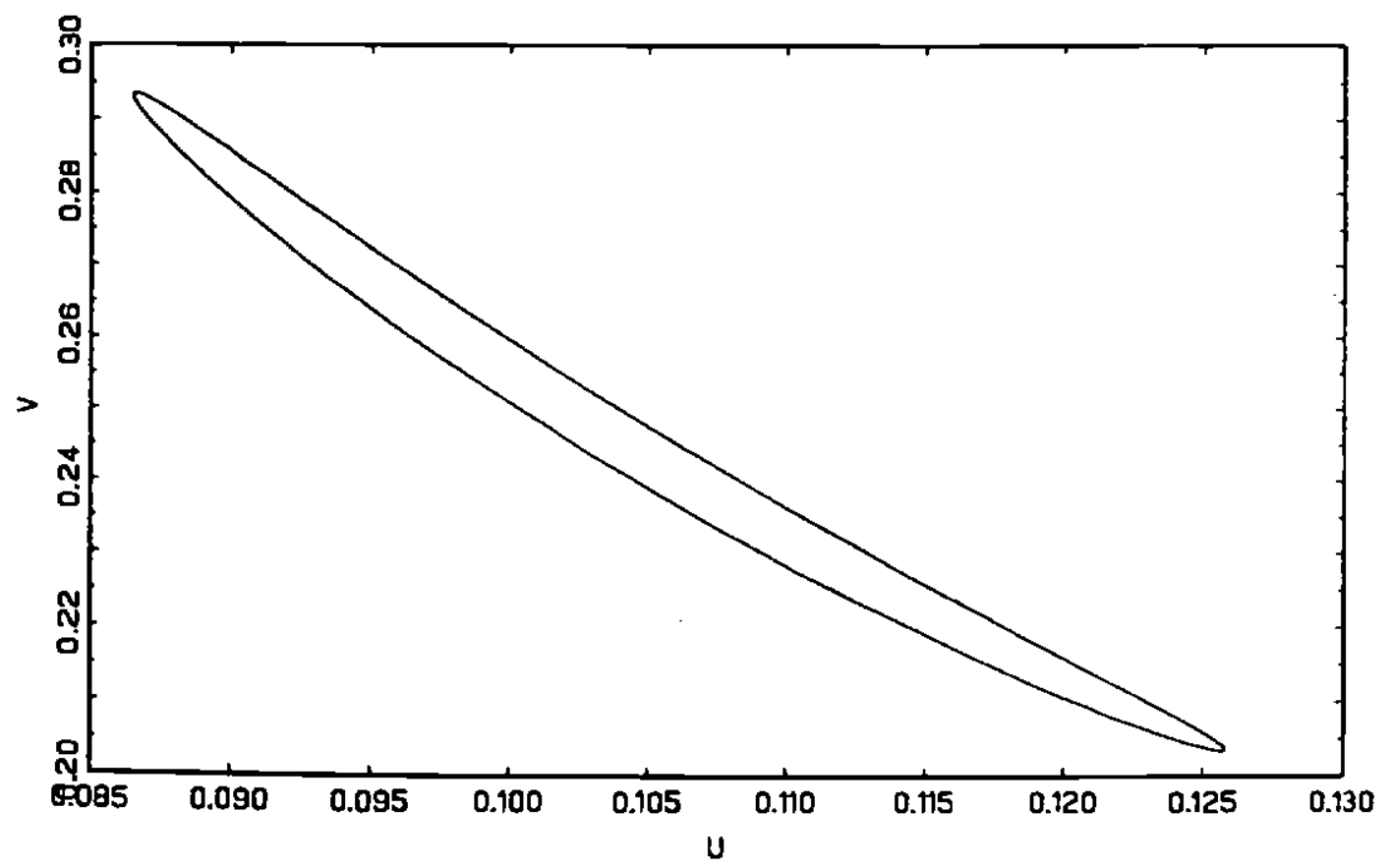


reallocation device in an efficient economy. Not only does creation rise as unemployment rises, which could be the direct result of higher unemployment in the matching function, but also creation efforts (vacancy posting) rise. Quite the opposite, the lower panel reveals the downward-sloping Beveridge curve associated with the decoupling of creation and destruction in an inefficient economy with unbonded specific investment. Contrary to the identifying assumption used in the literature on the role allocative vs. aggregate shocks in employment fluctuations (e.g., Abraham and Katz 1986, Blanchard and Diamond 1989), the same type of aggregate shock can lead to either an upward or a downward sloping Beveridge curve, depending on economic structure. ${ }^{26}$

In the presence of specific investment, imperfect bonding decouples creation and destruction not only in terms of timing, but also in terms of amplitude. Figure 6 presents the cyclical response of an economy identical to the efficient economy in figure 2 ( $c_{0}$, $\left.c_{1}, c_{2}>0\right)$, except that bonding is now imperfect $(0<\phi=1)$. Besides the obvious level effects, imperfect bonding disrupts the precise timing of destruction followed by immediate creation. Second, the smoothing of creation leads to more rather than less volatility in destruction. The joint-smoothing behavior is also disrupted. In this ineffcient case, destruction is too volatile and occurs too early relative to creation, leading to an unnecessarily prolonged and volatile period of unemployment accunulation.

Search Costs vs. Specific Investment. As we have seen, the nature of the creation costs that create the match surplus to be bargained over is a surprisingly central determinant of the cyclical dynamics in our economy. Inefficiency in decentralized-bargaining models that focus on search costs takes the form of distorted volatility, while creation and destruction remain synchronized. This is, for example, the one robust cyclical distortion that arises in the model of Mortensen and Pissarides (1993). ${ }^{27}$ Shifting the emphasis

\footnotetext{
${ }^{26}$ Similarly, one should be careful in using the correlation between creation and destruction to identify allocative vo. aggregate shocks (see Davis and Haltiwanger 1984).

${ }^{37}$ The Mortensen and Pissarides (1993) model also gives rise to negatively correlated creation and destruction, but that is a non-robust consequence of modeling choice in discrete time. It is assumed that workers whose jobs are deatroyed at time $t$ only join the unemployment pool at $t+1$. Thus, a negative
} 
Figure 6: Inefficient Decoupling of Creation and Destruction

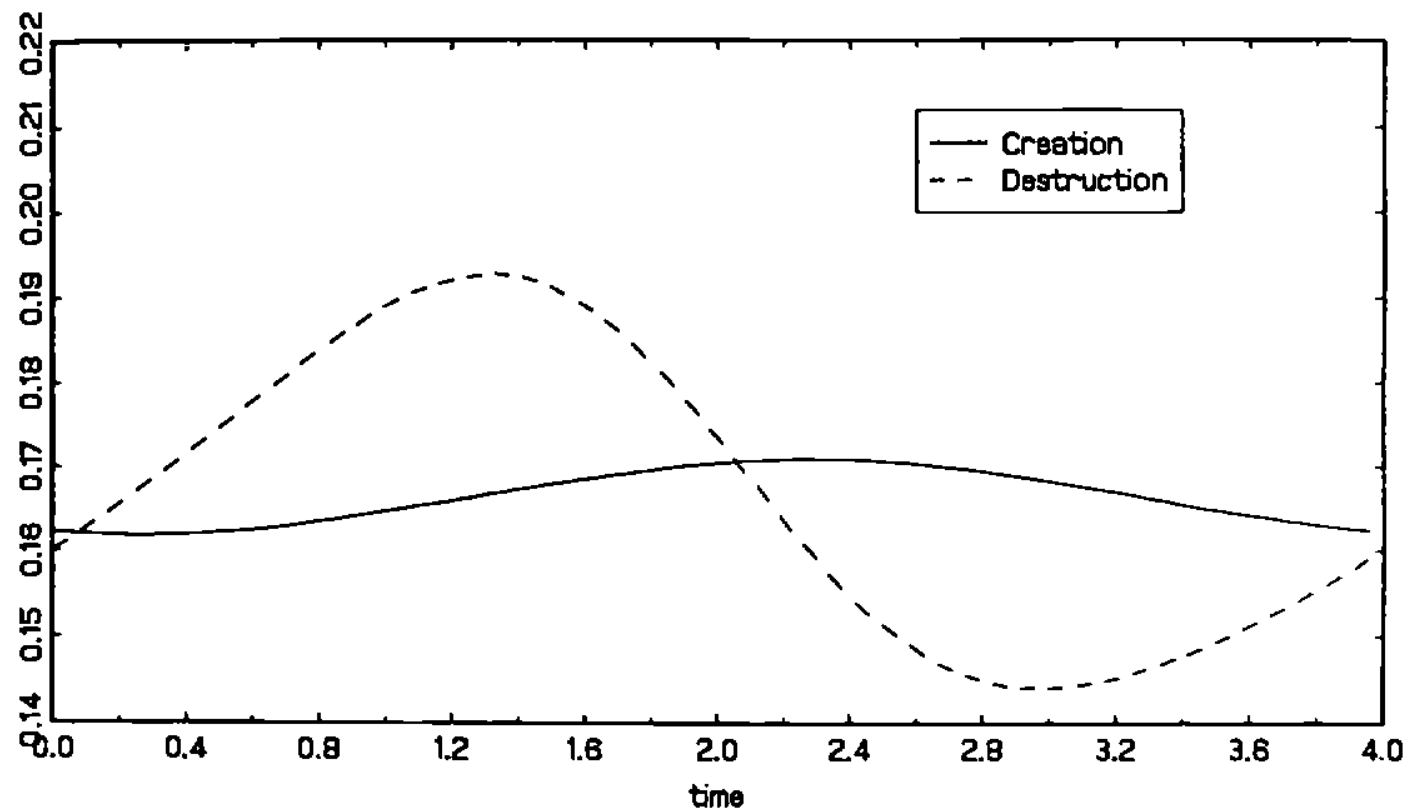


on the imperfect bonding of specific investment derails the tight synchronization of the reallocation process, both in terms of timing and amplitude.

The mechanics behind the cyclical response of the creation and destruction margins center around differences in the way and degree in which the shadow wage $\tilde{w}^{D}(t)$ absorbs aggregate shocks. Much of the difference between models based on search costs and models based on lack of bonding can be traced back to differences in wage "rigidity." As can be seen in equation (16), introducing greater worker bargaining power in the form of a larger share parameter $\beta$ leads to more sensitive wages to $S(t)$, a measure of the matchsurplus the worker can capture as an outside alternative. Thus, an inefficiently high $\beta$ leads to excessive wage sensitivity to hiring intensity $H(t) / U(t)$ in the labor market. That is why, in this case, strong workers tend to dampen the economy's cyclical responsiveness. Introducing greater bargaining power in the form of imperfect bonding and a positive $\phi$ shifts the weight in wage-determination from search costs to specific investment, as a determinant of the match surplus. This now renders the shadow wage excessively rigid and unresponsive to hiring intensity $H(t) / U(t)$ in the labor market. By decoupling creation and destruction, it changes the nature of recessions from being a time of intense. reallocation, in the right or wrong doses, to being a time of wasteful unemployment caused either by depressed hiring or increased destruction - unassociated with greater reallocation activity.

\section{Market Failures: Unemployment and Sclerosis}

In this section we turn to the effect of labor market inefficiencies on the pace of the creative destruction process. Under what conditions will the restructuring of the pro-

shock that increases destruction this period will only lead to high unemployment and cheap creation next period. This leads firms to delay creation this period until the next, giving rise to a negative conternporaneous correlation between creation and destruction, present even in an efficient economy. Notwithstanding, the counterpart of our strong synchronization result lies in the posilive correlation that they find between destruction at $t$ and creation at $t+1$. 
ductive system be excessively slow, and result in technological "sclerosis"? When will restructuring be, on the contrary, wastefully rapid, and result in what one might call technological "hyperkinesis"? Surprisingly, we find that, regardless of whether workers are excessively weak or strong, labor market inefficiencies whatever their direction always lead to sclerosis.

\subsection{Weak and Strong Workers}

To study the pace of creative destruction, we consider the economy in steady state as a tool of analysis. Our results will, nevertheless, be instructive about the average pace of reallocation in a fluctuating economy and even about the effect of relatively low-frequency cycles. ${ }^{28}$ In this subsection we derive an "equivalence" result that will be useful in the subsequent analysis. We show that there is a form of steady-state equivalence between the two bargaining power parameters $\phi$ and $\beta$, that allows us to compensate workers for a reduction in one parameter by increasing the other. We can thus divide the parameter space in two well-defined regions where workers are too "weak" and too "strong," even when one parameter indicates weakness and the other strength (e.g. $\beta<\eta$ and $\phi>0$ ).

We use a "*" to denote a variable in steady state. A steady state is an equilibrium path with constant $\left(\bar{a}^{*}, H^{*}, U^{*}\right)$, and requires a constant path for the exogenous variable $b^{\circ}$. The economy's equilibrium conditions (11)-(12) and (14)-(17) in steady state become

$$
\begin{gathered}
e^{-\gamma_{\bar{a}}^{*}}-\left[\tilde{w}^{* D}-b^{*}\right]=0, \\
\hat{c}^{D}=P V\left(\bar{a}^{*}\right), \\
U^{*}=\bar{L}-\frac{H^{*}}{\delta}\left[1-e^{-\delta \bar{a}^{*}}\right],
\end{gathered}
$$

\footnotetext{
${ }^{23}$ With increasing marginal creation costs, the average level of different quantities in a fluctuating economy may be different from their steady-state level. This is because, given the convexity of $C(H, U)$ in $H$, volatility in $H$ makes creation more expensive on average.
} 
where

$$
\begin{gathered}
\tilde{w}^{* D}=\frac{H^{*}}{U^{*}} \frac{\beta}{1-\beta}\left[\phi I_{H}^{*}+S^{*}\right], \\
\tilde{c}^{* D}=\left(1+\frac{\beta}{1-\beta} \phi\right) I_{H}^{*}+\frac{1}{1-\beta} S^{*}, \\
P V\left(\bar{a}^{*}\right)=\frac{\left[1-e^{-(r+\delta) \bar{a}^{*}}\right]}{(r+\delta)}-\frac{\left[e^{-\gamma^{*}}-e^{-(r+\delta) \bar{a}^{*}}\right]}{(r+\delta-\gamma)} .
\end{gathered}
$$

We can now state our equivalence result, which is proved formally in appendix A.2. Consider an economy with positive search costs $\left(c_{2}>0\right)$. Consider any pair $\left(\phi_{0}, \beta_{0}\right) \epsilon$ $[0,1] \times] 0,1\left[\right.$, and the steady state $\left(\bar{a}_{0}^{*}, H_{0}^{*}, U_{0}^{*}\right)$ that corresponds to $(\phi, \beta)=\left(\phi_{0}, \beta_{0}\right)$. Then one can find a (weakly) decreasing function $f_{0}(\phi)$ over $[0,1]$ such that, for any $\phi \in[0,1]$, the corresponding steady state to $(\phi, \beta)=\left(\phi, f_{0}(\phi)\right)$ is $\left(\vec{a}_{0}^{*}, H_{0}^{*}, U_{0}^{*}\right)$. Naturally, we must have $f_{0}\left(\phi_{0}\right)=\beta_{0}$.

Another way to state the result is that any steady-state outcome $\left(\vec{a}_{0}^{*}, H_{0}^{*}, U_{0}^{*}\right)$ corresponds to a whole schedule $\left(\phi, f_{0}(\phi)\right)$ of bargaining parameters. Quite intuitively, this schedule is decreasing because a rise in one bargaining parameter must be offset by a fall in the other, if we are to keep worker bargaining power and the steady-state outcome unchanged. It is in this sense that the parameters $\phi$ and $\beta$ are "equivalent" in steady state.

This result allows us to divide the bargaining-parameter space into two clearly delineated regions of excessively "weak" and "strong" workers. In figure 7, we first draw the "efficient" schedule $\left(\phi, f^{E}(\phi)\right)$ that corresponds to the efficient steady-state. By the result in section 2.4 , this schedule crosses the $\beta$-axis at the point $(\phi, \beta)=(0, \eta)$. All equivalence schedules that start below this point correspond to weaker workers than is efficient, and remain below the efficient schedule. ${ }^{29}$ All schedules above correspond to stronger-than-efficient workers, and remain above the efficient schedule. Thus the efficient schedule divides the parameter space into two regions: a region below it where workers

\footnotetext{
${ }^{29}$ Schedule cannot cross because each is drawn for a different steady-state equilibrium.
} 
Figure 7: Strong and Weak Workers Aegions

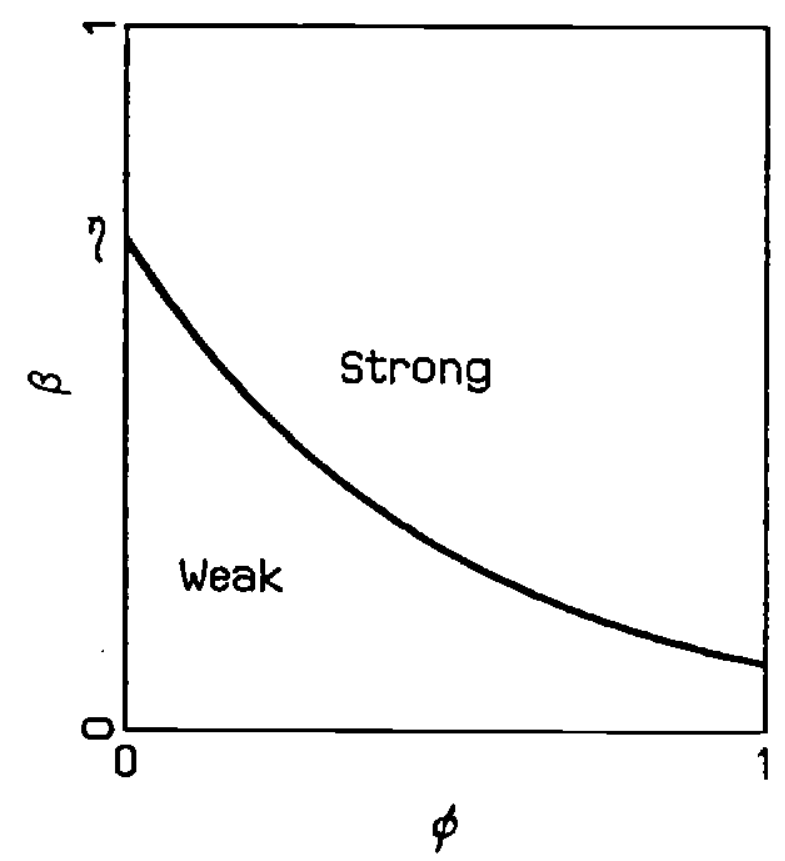


are weak, and a region above it where they are strong.

\subsection{Unemployment and Sclerosis}

With the above classification of worker bargaining power in steady-state, we are ready to characterize the direction of inefficiency in the two regions. It is clear from (18)-(20) that $\left(U^{*}, \vec{a}\right)$ are sufficient statistics to describe a steady state, since $H^{*}$ can then be obtained from the unemployment equation (20). We will thus focus on those two variables. Our results are clearest when we assume $c_{1}=0$. Because differentiating between $c_{1}$ and $c_{0}$ is much less interesting in steady state than over the cycle, we choose to assume $c_{1}=0$ from now on and present our results in their clearest form.

Under- and Over-Employment. Figure 8 traces the curve in $\left(U^{*}, \bar{a}^{*}\right)$-space that is generated by increasing $\beta .{ }^{30}$ The trough of the curve corresponds to the efficient value $\beta=f^{E}(\phi)$. It is clear that unemployment is increasing with $\beta$. In other words, the strong-worker region is characterized by under-employment, and the weak-worker region by over-employment. This is what one would expect, given that strong workers take an excessively large share of profits and discourage labor demand, while weak workers take an excessively small share and encourage labor demand. As discussed earlier, the economy offsets an increase in the worker bargaining power with an endogenous rise in unemployment that weakens workers and restores adequate firm profitability.

More formally, appendix A.3 shows that $d U^{*} / d \beta>0$ in the weak-worker region and in the strong-worker region near the efficient equivalence curve. Although we could not show formally that it is positive everywhere in the strong-worker region, this was true in all the numerical examples we have tried. Moreover, the appendix shows that $U^{\bullet} \rightarrow \bar{L}$ as $\beta \rightarrow 1$.

Technological Sclerosis. If we turn to the scrapping age $\bar{a}^{*}$, we find in figure 8 that it is

\footnotetext{
${ }^{30}$ The figure was generated with the following parameters: $r=0.065, \gamma=0.028, \delta=0.15, \eta=0.5, b^{\circ}$ $=0.390$ and $L=1$. Creation cost parameters are $c_{0}=0.399, c_{1}=0$ and $c_{2}=0.004$. The bargaining parameters $\phi=0.3$ and $0.05 \leq \beta \leq 0.65$.
} 
Figure 8: Effects of Increasing $\beta$ in Steady State

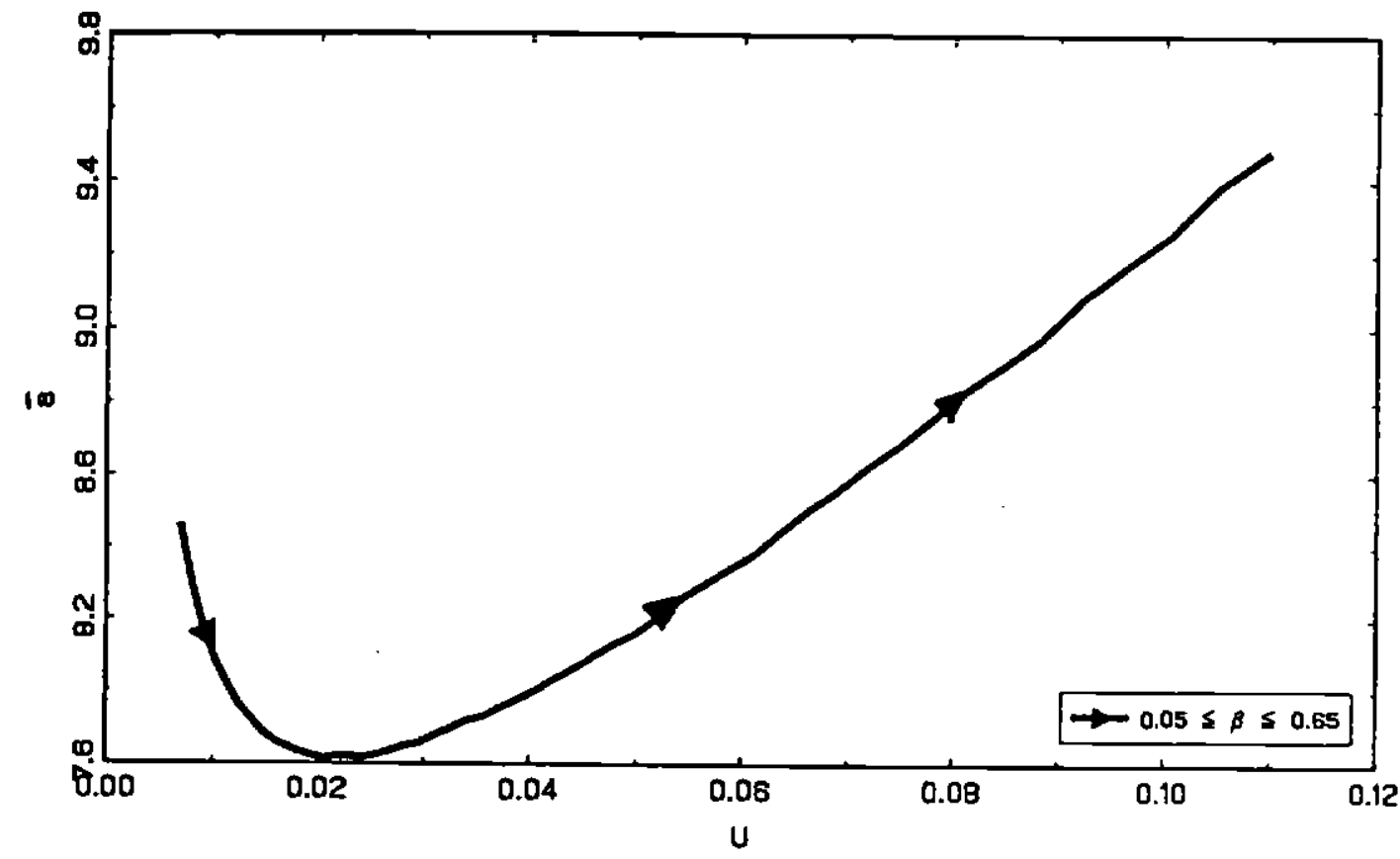


minimized at the efficient level of $\beta$. Thus, unlike what happens with unemployment, the economy exhibits the same direction of inefficiency for $\bar{\sigma}^{*}$ in the weak- and strong-worker regions. Appendix A.3 shows formally that, in both regions, $\bar{a}^{*}$ is above its efficient value. Labor market failures whatever their direction always lead to sluggish renovation anid technological sclerosis. Sclerosis is thus a state of affairs that any policy program will most likely have to face.

To get an intuition for this result, we set $z^{*}=0$ and write steady-state welfare as follows

$$
W^{*}=\left[K_{0}+\frac{p^{*} M+\tilde{w}^{* D} \bar{L}}{r-\gamma}\right] A(0) \text {. }
$$

This expression splits welfare in terms of the shadow income flows that go to different factors of production. The first term $K_{0}$ corresponds to the present value of income that goes to the owners of the initial distribution of production units. The second term is the discounted value of income that flows to the owners of the intermediate input $\left(p^{*} \bar{M}\right)$ and to workers $\left(\tilde{w}^{* D} L\right)$. Note that the shadow wage goes to both employed and unemployed workers, because the latter also receive an expected flow $\tilde{w}^{* D}$ based on the probability of finding a job (see equation 29 in appendix A.1).

Now, we need to compare $W^{*}$ across steady states that correspond to different configurations of $(\phi, \beta)$. The problem is that if we want to talk meaningfully about the parameters $(\phi, \beta)$ that maximize $W^{*}$, we need to start from the same initial distribution of jobs. But this means that we will not be generally starting in steady state. For this reason, despite the fact that our result is quite general, we limit our discussion to the limit case where $(r-\gamma)$ goes to zero. In this undiscounted case, initial conditions do not matter and we can ignore the term $K_{0}$.

In this case, equation (24) shows that the bargaining parameters that maximize welfare are the ones that maximize the shadow wage $\tilde{w}^{* D}$. But the exit condition (18), which can be written as $\tilde{w}^{* D}=e^{-\gamma \bar{a}^{*}}+b^{*}$, implies that maximizing $\tilde{w}^{* D}$ amounts to minimizing $\bar{a}^{*}$. Thus the efficient parameter configurations are the ones that minimize $\bar{a}^{*}$. 
Intuitively, sclerosis in this economy - whether workers are weak or strong - is a result of the undervaluation and misuse of labor as a factor of production. It is when labor has the highest shadow value that the pressure to exit is highest on outdated techniques and the pace of renovation is fastest. ${ }^{31}$ When workers have little bargaining power, the reason for the undervaluation of labor is clear. When workers are strong, their shadow wage should be high in partial equilibrium. But in general equilibrium, powerful workers discourage job creation, leading to increased unemployment and a depressed shadow price of an unemployed worker. ${ }^{32}$

\section{Policy}

In this section we turn to government policy. What kind of policies can improve the pace and cyclical features of the creative destruction process? What would be the effect of those policies on unemployment and sclerosis? A simple answer is to recommend that governments try to fix their problems at the root, and change the institutional aspects of the labor market that are the source of what is essentially a supply-side problem. This is often politically infeasible. In the absence of an institutional cure, we study two classes of policies - production and creation incentives - that can provide at least a partial cure for the economy's ills. As we will see, those two types of policies affect the economy's unemployment and sclerosis problems very differently, and could actually be combined optimally to bring the economy to its efficient outcome.

\footnotetext{
${ }^{31}$ Without making the connection with bargaining power, Salter (1960) describes the relation between wages and scrapping as follows: "When real wages are high, standards of obsolescence are high, and a high level of replacement investment ensures rapid adjustment to new methods. Conversely, when real wages are low, the capital stock is adjusted slowly to new methods and average productivity is lower" (p. 73)."

${ }^{35}$ Note that this discussion is about shadow wages, not actual wage flows. In fact, one can show that - with continuous Nash bargaining - average wage payments are generally maximized in the interior of the atrong-worker region. Politically, labor may thus find it advantageous to push for an outcome where workers have greater than efficient bargaining power.
} 


\subsection{Production and Creation Incentives}

At first sight, policies that directly encourage creation - e.g., an investment tax credit and those that directly encourage production - e.g., a reduction in the corporate income tax - may appear equivalent. As long as their benefits are the same in present value terms, shouldn't they affect investment in the same way? In the presence of two margins, this argument misses important differences in the way those policies affect destruction. Creation incentives directly affect the decision to invest, and, through more intense hiring in the labor market, indirectly prop up wage pressures on exiting jobs. Production incentives not only affect investment decisions, but also directly encourage firms to keep outdated production units longer in operation.

We introduce production incentives in our model by simply reinterpreting the subsidy $z(t)$ as such. We introduce creation incentives by assuming a subsidy $i(t) A(t)$ per production unit created. ${ }^{30}$ In this case, the subsidy must be subtracted from the effective creation cost in equilibrium conditions (14)-(17): $:^{34}$

$$
\left[\tilde{c}^{D}(t)-i(t)\right] A(t)=\int_{t}^{t+T(t)}[A(t)-A(s-\tilde{a}(s))] e^{-(r+\delta)(s-t)} d s,
$$

We analyze those policies in a steady-state economy in terms of the sufficient statistics $\left(U^{*}, \vec{a}^{*}\right)$. Appendix A.5 shows that an increase in the production incentive $z^{*}$ reduces unemployment but increases the scrapping age $\bar{a}^{*}$. The subsidy protects outdated production units by absorbing the cost pressures to destroy them. The impact of creation incentives is quite different. The appendix shows that an increase in $i^{*}$ reduces the scrapping age, while its effect on unemployment is ambiguous. A creation subsidy leads to

\footnotetext{
${ }^{33}$ Distinguishing realistically between production and creation incentives can be quite tricky. Consider an investment tax credit. Although it is primarily a creation incentive, it can act simultaneously as a production incentive if, through a Keynesian multiplier effect, it leads to an aggregate demand expansion. As a second example, consider a tax holiday for new investments. It acts effectively as a creation incentive if it lasts lese than a production unit's lifetime, but as a production incentive if it lasts more.

${ }^{34}$ We apply full bonding to the subsidy because it is not match specific: if the worker quits, the firm will atill be able to get the same aubsidy by hiring another employee.
} 
greater hiring intensity that increases wage pressures to destroy outdated production units. Its effect on unemployment depends on the degree to which destruction offsets the positive effect of increased creation on employment.

Figure 9 illustrates the steady-state effects of production and creation incentives. The solid and dashed lines represent the steady states that correspond to a range a values for $z^{*}$ and $i^{*}$, respectively (subsidies are positive and taxes are negative). The two lines intersect at the point where $z^{*}=i^{*}=0$. The figure was generated with what we take to be a realistically small value for the search cost. ${ }^{35}$ In this small- $c_{2}$ case, the two policies appear almost "orthogonal": production subsidies are the appropriate tool to reduce steady-state unemployment with little effect on $\vec{a}^{*}$, while creation subsidies are the tool to reduce sclerosis with little effect on $U^{*}$.

How do those conclusions carry over to temporary increases in $z$ and $i$ ? If we think of fluctuations as being driven by $z(t)$, our previous analysis of business cycles indicates that a temporary production subsidy will generally have a qualitatively similar effect to a permanent one - lower $U(t)$ and higher $\bar{d}(t)$. However, the result that the effect on $\bar{z}(t)$ is small when search costs are small does not generalize. We saw in section 3.2 that recessions can have a strong cleansing effect on the productive structure even when search costs are zero. ${ }^{36}$ Similarly, the intuition for why permanent creation incentives decrease d clearly carries over to temporary ones. It will still be the case that the resulting rise in hiring incentives will increase wage pressures on exiting production units.

\footnotetext{
${ }^{35}$ The figure was generated with the same parameters as figure 8 . We chose to model a $\phi$-inefficient economy with bargaining parameters $\beta=0.5$ and $\phi=0.3$. We calibrated $p^{*}$ and the creation cost parameters $c_{0}$ and $c_{2}$ (we set $c_{1}=0$ because it is not central for sleady-stale issues) so as to yield an unemployment rate $U^{\bullet}=0.065$, a hiring intensity of $H^{\bullet} / U^{\bullet}=3$, and a search cost $S^{\bullet}$ equal to 3 weeks of the leading technology's quasi-rents. Calibration was done with zero government incentives $\left(i^{*}=z^{*}=0\right)$. It is the last restriction on $S^{*}$ that gives $u s$ the small value for $c_{2}$. The implied scrapping age for the calibrated economy is $\overline{\mathrm{a}}^{\circ}=\mathbf{8 . 4 7}$ years.

${ }^{36}$ The cleansing eftect of recessions arises in the imperfect-insulation case when $c_{1}>0$. A large $c_{1}$ is much less important in stendy state. We generated figure 9 , for example, with a large $c_{1}$ and obtained a qualitatively very similar figure.
} 
Figure 9: Increases in Production and Creation Incentives

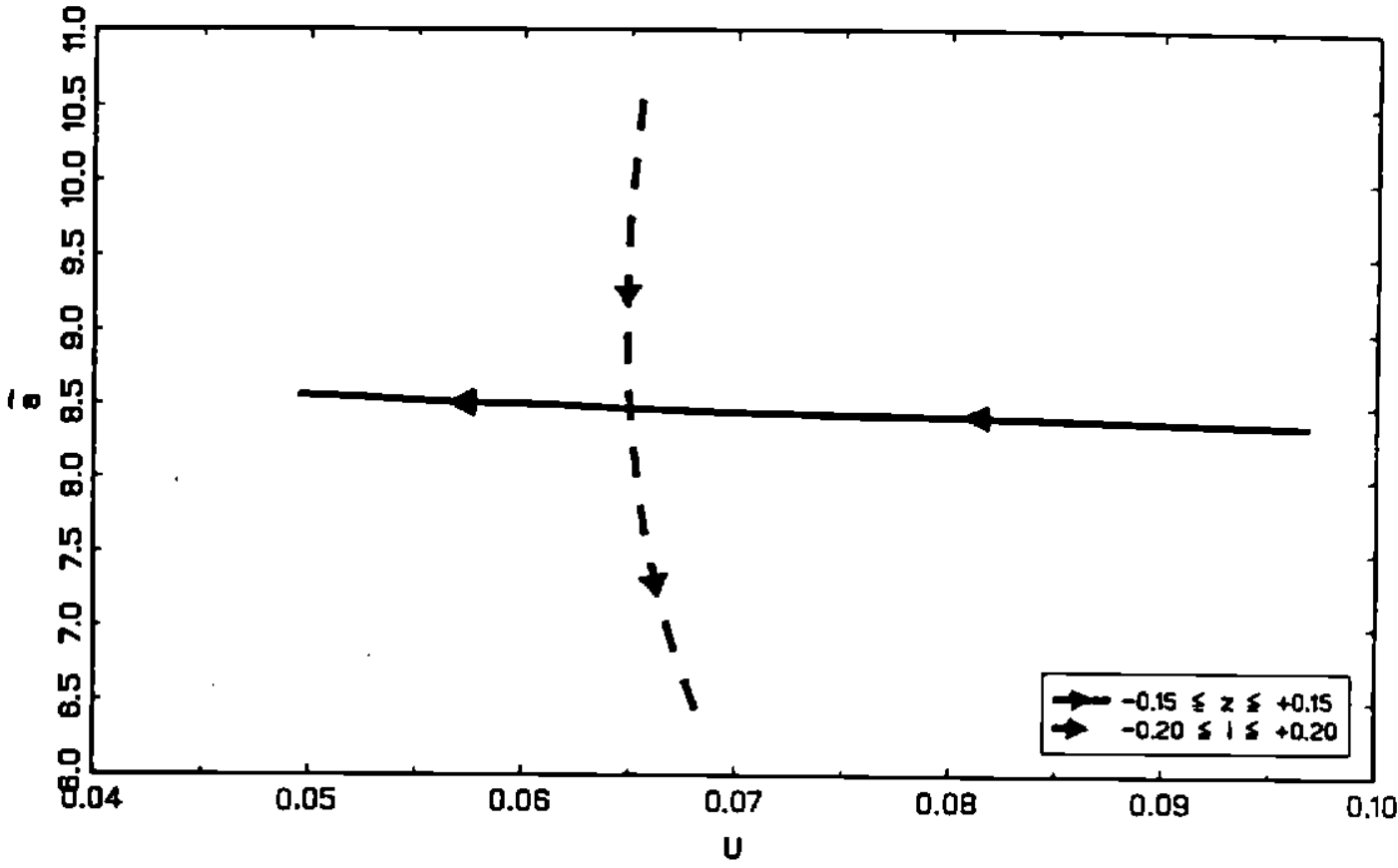




\subsection{Expansionary Policy, Liquidationism, and Accelerationism}

Having characterized the effects of our two policy instruments, we can now assess them in terms of welfare. We concentrate on the strong-worker region, where the economy suffers from high unemployment and technological sclerosis, and study the welfare effects of introducing a small production or creation incentive.

Production Incentives and the "Liquidationist" View of Recessions. In the strongworker region, the welfare effect of expanding the economy through a production subsidy appears to be ambiguous. On the one hand, economic expansion can relieve the unemployment problem; on the other it exacerbates the state of technological sclerosis. Could the second effect dominate the first and make the expansion undesirable on the whole? In this case, what the economy really needs would be a recession that "cleanses" its productive structure - an idea reminiscent of the pre-Keynesian "liquidationist" view (see DeLong 1991).

To address this question, let us first look at the steady-state welfare effects of a small production subsidy $d z^{*}$ starting from $z^{*}=0$. As discussed in section 4.2 , a meaningful welfare comparison across steady states can only be undertaken in the limit case where $(r-\gamma)$ goes to zero and initial conditions do not matter. In this case appendix A.4 shows that the change in the flow of steady-state welfare in response to policy can be expressed in terms of the response of the hiring intensity $H^{*} / U^{*}$ :

$$
\left.d \omega^{*}\right|_{z=i=0}=\left(\tilde{w}^{* D}-\tilde{w}^{*}\right) U^{*} \frac{d\left(H^{*} / U^{*}\right)}{H^{*} / U^{*}},
$$

where $\tilde{w}^{S} \equiv-C_{U}$ represents the social shadow value of an unemployed worker. It is easy to see that, when workers are strong, their decentralized-equilibrium shadow wage $\tilde{w}^{D}(t)$ is always greater that their social shadow wage $\widetilde{w}^{S}(t) .{ }^{37}$ Since a creation incentive always increases $H^{\bullet} / U^{*}$ (see appendix A.5), equation (26) shows that a small production subsidy

\footnotetext{
${ }^{37}$ Since we are comparing $\tilde{w}^{S}$ and $\tilde{w}^{D}$ for the same aggregate quantities, this statement corresponds to the simple partial-equilibrium result that the shadow wage is increasing in the bargaining power of workers.
} 
is always welfare-improving in the strong-worker region. ${ }^{38}$ The exit condition (14) gives a good intuition why the liquidationist view cannot hold here. The "cleansing" that results from depressing the economy amounts to moving a worker from a job at the destruction margin to the unemployment pool. Since the exiting worker produces $\tilde{w}^{* D}$ on the job but has a social value of only $\tilde{w}^{* S}$ in the unemployment pool, this produces a social loss of $\left(\tilde{w}^{* D}-\tilde{w}^{* S}\right)>0$.

This intuition carries over to temporary recessions as well, since the inequality $\tilde{w}^{s}(t)<$ $\tilde{w}^{D}(t)$ holds also outside of steady state. Figure 10 shows the time path of the flow of welfare that corresponds to the business-cycle simulation in figure 6, assuming the business cycle is driven by fluctuations in $z(t)$. It is clear that the flow of welfare is procyclical.

Creation Incentives and "Accelerationist" policies. Let us now turn to the steady-state welfare effect of a small creation subsidy $d i^{*}$ starting from $i^{*}=0$. In the strong-worker region, this policy would provide a partial cure for sclerosis by reducing $\bar{a}$. Although its effect on unemployment is ambiguous, we know by equation (26) that, since it increases $H^{*} / U^{*}$ (see appendix A.5), it must be welfare-improving.

Naturally, a creation subsidy can only be beneficial up to a point. When the subsidy becomes too large, the economy will suffer from a state of "hyperkinesis" with restructuring happening at an excessively fast and costly pace. Government policy can thus give rise to a new phenomenon of excessively low $\bar{a}^{*}$, that we saw would not arise out of pure bargaining-related labor market failures.

The case of Singapore as documented by Young (1992) seems to match well this pattern of government-induced high investment and excess restructuring. In the 1970s and 1980s aggregate investment in Singapore reached phenomenal levels as a share of GDP., peaking at $43 \%$ in 1984 . High investment was to a great extent related to a combination of tax incentives and widespread government participation in the finance of local compa-

\footnotetext{
${ }^{36}$ Conversely, one can show that in the weak-worker region $\left(\tilde{w}^{* D}-\tilde{w}^{* S}\right)<0$ and a small production tax is welfare-improving.
} 
10.a: Aggregate Demand Distortion

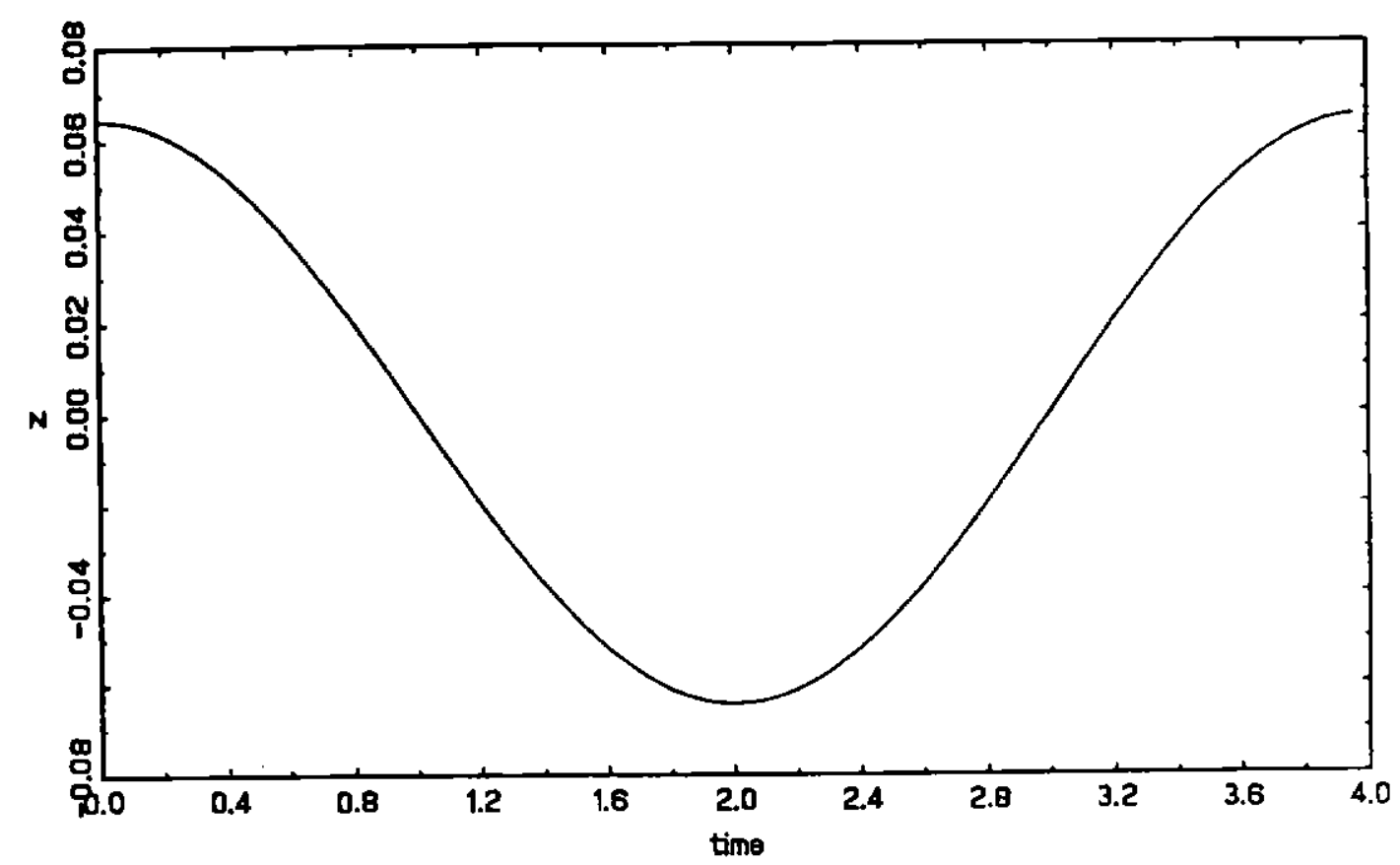

10.b: Flow of Welfare [Detrended]

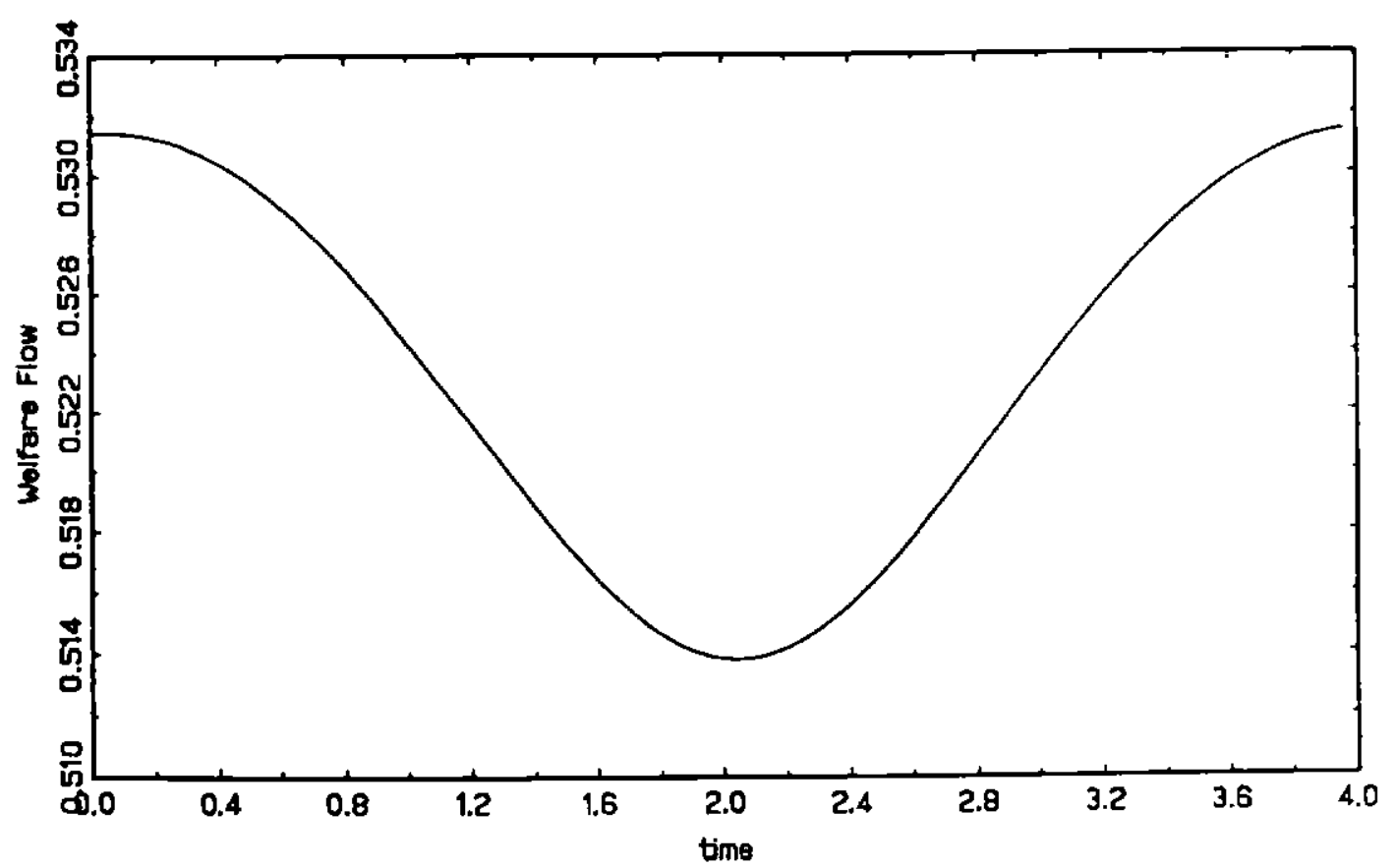


nies (financed primarily by labor income taxation and forced saving). Not surprisingly, during the same period the economy was undergoing one of the world's highest rates of structural change in manufacturing, moving from one industry specialization to the next at a very fast pace. Young's assessment of the Singaporean economy is that it invested and restructured at excessively high rates. Compared to a laissez-faire economy like Hong Kong, it reached a comparable growth rate but at a much higher cost.

\subsection{Optimal Dynamic Policy}

We have seen that production and creation subsidies affect the economy's creation and destruction margins differently. This raises the question whether a judicious combination of the two policies can correct the price signals that distort those two margins and restore full efficiency.

In fact, the solution to this problem is quite simple. We can restore efficiency if we use the creation subsidy to correct the distortion in the effective creation cost signal, and the production subsidy to correct the shadow wage signal. In other words we need to set

$$
\left\{\begin{array}{l}
i(t)=\tilde{c}^{D}(t)-\tilde{c}^{S}(t)=\frac{\beta \phi}{1-\beta} I_{H}(t)+\frac{\beta-\eta}{(1-\eta)(1-\beta)} S(t) ; \\
z(t)=\tilde{w}^{D}(t)-\tilde{w}^{S}(t)=\frac{H(t)}{U(t)} i(t) .
\end{array}\right.
$$

Taking (25) into account, it is straightforward to verify that the equilibrium conditions (14)-(15) of the decentralized economy subject to those subsidies are identical to the equilibrium conditions (7)-(8) of the corresponding efficient economy.

Consider what this implies for a strong-worker economy in steady state. Such an economy suffers from high unemployment and sclerosis. In terms of figure 9 , we need to move it in the southwest direction. This can be achieved by a combination of positive production and creation subsidies. The former mainly reduces unemployment (westward movement), and the latter mainly relieves sclerosis (southward movement). Thus, the presence of strong workers - due to imperfect bonding or a large worker-share parameter - requires that firms be compensated via a combination creation and production 
subsidies. The opposite policies are required when workers are weak.

In addition to the level effects above, equations (27) also solve for the cyclical aspect of optimal policy design. In order to isolate this cyclical dimension, we remove level effects by focusing on cases where $(\phi, \beta)$ lie along the efficient steady-state equivalence curve described in section 4.1..$^{39}$ Figure 11 shows $-p(t)$ in panel (a), the optimal creation subsidy in panel (b), and the optimal production subsidy in panel (c). ${ }^{40}$ The last two panels present curves for different configurations of bargaining parameters $(\phi, \beta)$ along the efficient equivalence curve. It is clear that optimal creation and production subsidies are countercyclical, and more so as the configuration of gives greater weight to imperfect bonding $\phi$. As we have seen in section 3.2, as workers derive more of their bargaining strength from imperfect bonding $\phi$ rather that from the share parameter $\beta$, the shadow wage becomes increasingly rigid. Relative to the efficient economy, workers become excessively strong during recessions, when wages do not fall enough and unemployment is too high, and excessively weak during expansions for the opposite reason. This explains why firms must be given incentives during recessions, and taxed during expansions.

\section{Conclusion}

Economies are hardly static entities occasionally perturbed by various shocks. Rather, they are dynamic, continuously restructuring objects, with large and sustained factor reallocation flows. Technological unemployment, as described by Schumpeter, is a natural result of the frictions indigenous to the process of reallocation. But it comes with no guarantee that unemployment is at the right level, that restructuring occurs at an adequate pace, or that the cyclical features of reallocation flows are efficient.

In this paper, we have focused on the disruptive effects on creative destruction of

${ }^{39}$ This guarantees that in steady state workers are neither too strong nor too weak. It does not guarantee that the same is true on average in an economy with ongoing fucluations. However, figure $1 /$ below shows that this difference is second order.

${ }^{40}$ The economy in question has the same parameters as in figures 2 and 6. 
11.a: Business cycle indicator

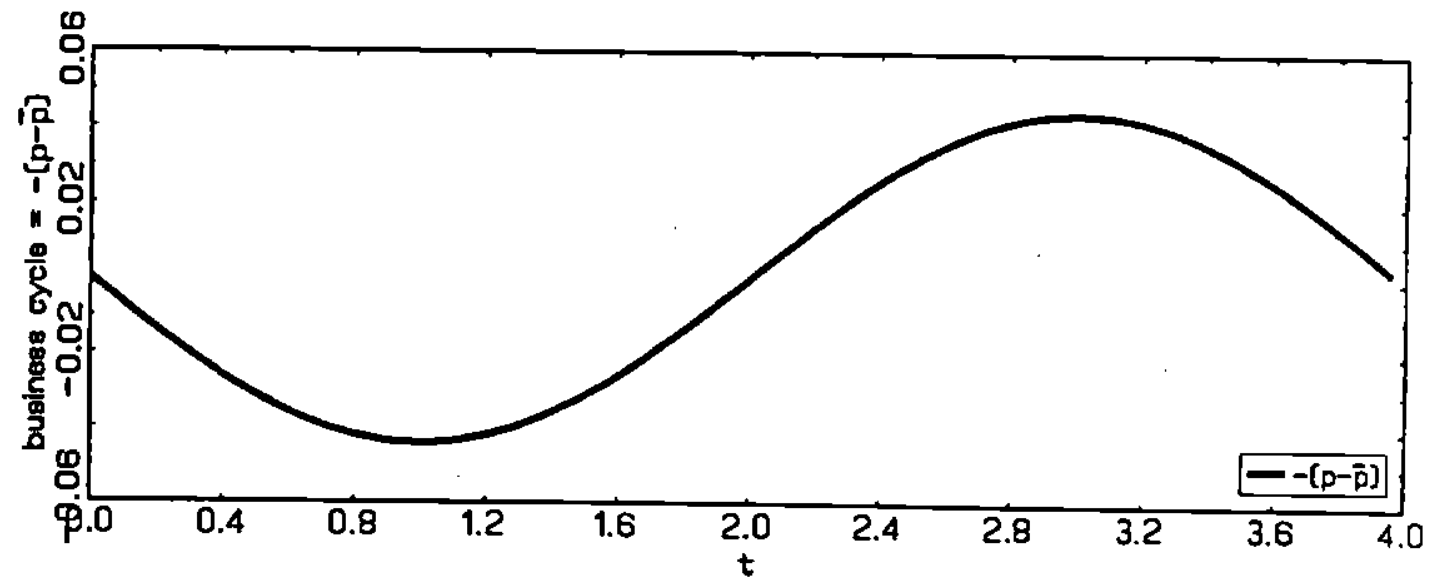

11.b: Optimal Creation Incentives

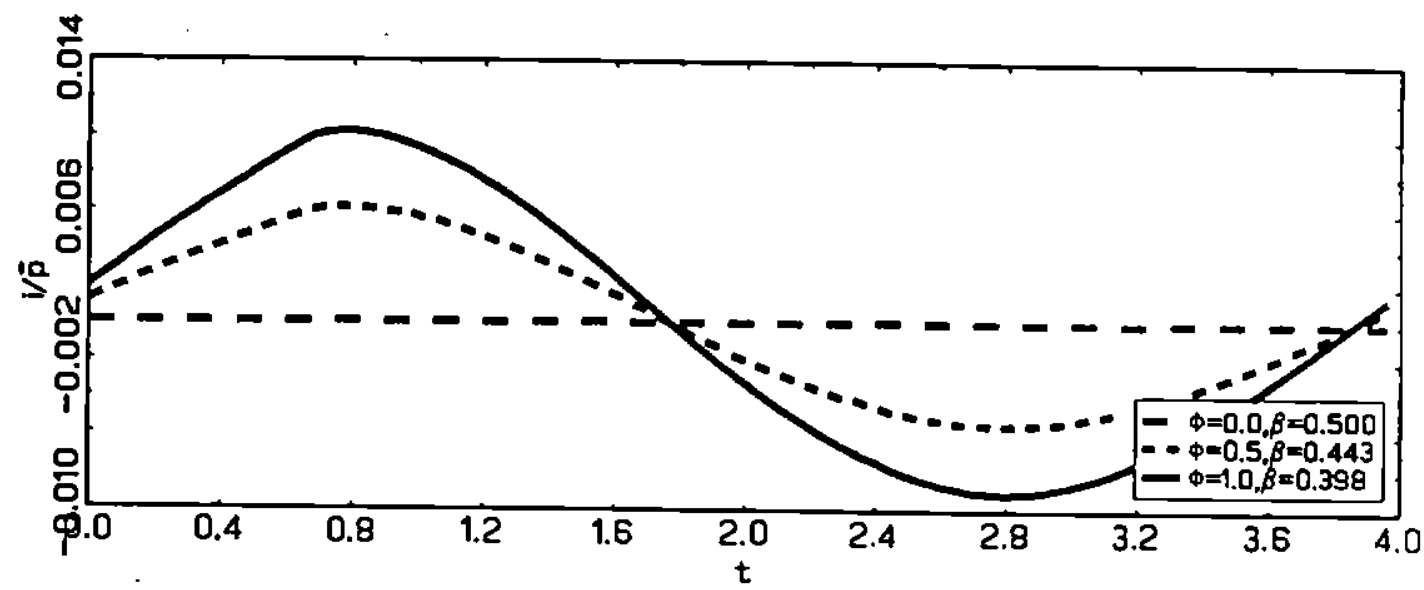

11.c: Optimal Production Incentives

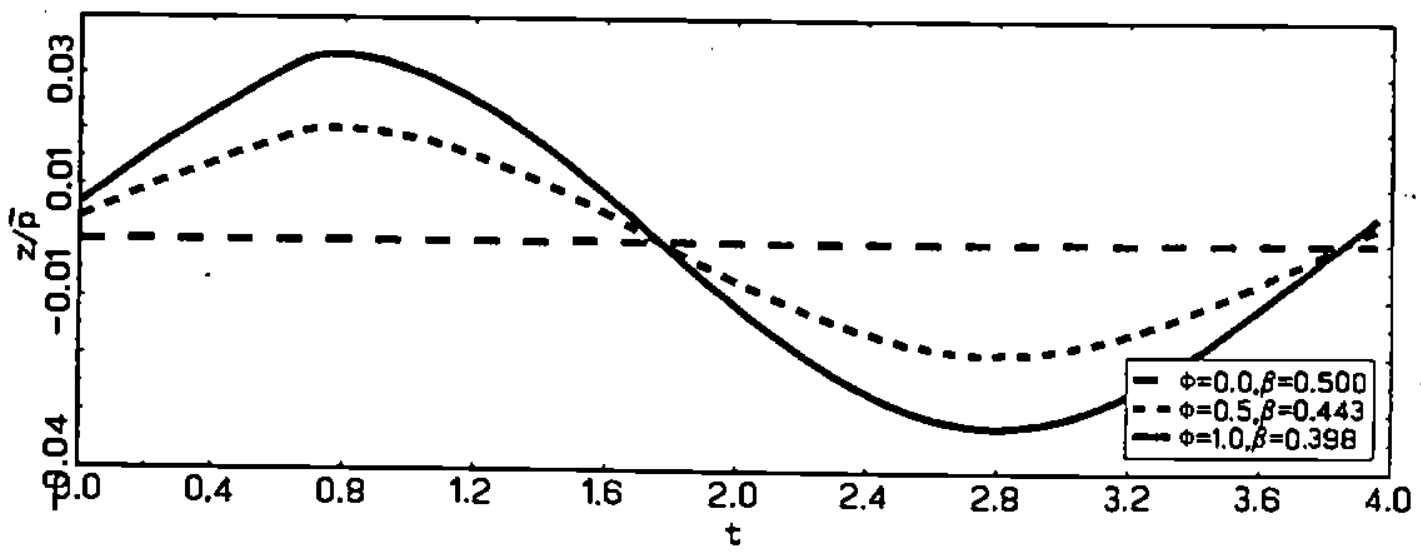


a malfunctioning labor market where, deprived of the benefits of a Walrasian auctioneer, workers and firms must meet and bargain in a decentralized manner. Interestingly, we found that labor-market problems systematically lead to technological "sclerosis," whether the bargaining-power balance is favorable or unfavorable to workers. The basic reason is that, in general equilibrium, labor-market inefficiencies lead to a misuse and undervaluation of labor, which loosens the cost pressures to shut down outdated production units. Simultaneously with sclerosis, excessive technological unemployment can arise if the bargaining power of workers is too high.

With strong workers, an effective policy response to sclerosis lies in the introduction of incentives to create which, by increasing the intensity of hiring in the labor market, prop up wage pressures to scrap old technology. But, as far as high unemployment is concerned, hiring incentives may not be a good remedy precisely because they lead to increased scrapping. To partially reduce their effect on the destruction margin, creation incentives must be complemented by means of policies that encourage firms to keep their workers. Even the much-maligned imposition of firing costs may provide an acceptable cure for unemployment, provided that they are conceived as a supplement to vigorous hiring incentives.

Decentralized bargaining in the labor market can also disrupt the response of creative destruction to aggregate shocks. In an efficient economy, there are strong reasons to concentrate reallocation efforts in recessions, when the opportunity cost of generating the unemployment needed to facilitate reallocation is low. Recessions should be times of intense reallocation, when creation as well as destruction and unemployment are high. With decentralized bargaining this process can be derailed, and creation can be decoupled from destruction. Those effects are due to a form of real wage rigidity brought about by a lack of bonding of match-specific investment - rather than the more usual searchcost related factors. Such decoupling is consistent with the evidence on gross labor flows documented by Davis and Haltiwanger $(1990,1992)$. Their evidence shows that increased destruction and unemployment in recessions are associated with low rather 
than high creation. Moreover, the apparent "smoothing" of creation over the cycle finds no counterpart in the behavior of destruction (see Caballero and Hammour 1994).

Rather than being primarily times of increased reallocation intensity, we interpret recessions as times of productivity cleansing. This does not mean that we find a case for a revived "liquidationist" view of refessions as desirable. Increased unemployment in a recession is essentially wasteful in this context. When workers are strong, their shadow wage in production is greater than their social shadow value, and the difference is lost when they are moved from production to unemployment. In the absence of an institutional cure for malfunctioning labor markets, cyclical policy may be called for. In the face of wage rigidity induced by imperfect bonding, the provision of counter-cyclical incentives to firms may help improve the timing of labor-reallocation flows over the cycle. 


\section{A Appendix}

\section{A.1 Decentralized Bargaining Equilibrium Conditions}

This section derives the decentralized bargaining equilibrium conditions (14)-(17) for our economy. Let $W^{f}(t)$ denote the value to the firm of a job created at $t, W^{e}(t)$ the human wealth of a worker just employed in such a job, and $W^{u}(t)$ the human wealth of an unemployed worker. The setup cost of a single production unit is $I_{H}(t)$. Assuming positive free entry, we equate the value of a job to the match-specific creation costs that cannot be bonded away:

$$
\left[\phi I_{H}(t)+S(t)\right] A(t)=W^{f}(t)
$$

Turning to workers' human wealth, the expected utility flow received by an unemployed worker is given by

$$
\tilde{w}^{D}(t) A(t)=\frac{H(t)}{U(t)}\left(W^{e}(t)-W^{u}(t)\right)
$$

It is equal to the instantaneous probability $H(t) / U(t)$ of finding a job times the resulting gain in human wealth $\left(W^{e}(t)-W^{u}(t)\right)$. This quantity determines the simple arbitrage condition governing the evolution of unemployed workers' human wealth:

$$
r W^{u}(t)=\tilde{w}^{D}(t) A(t)+\frac{d W^{u}(t)}{d t}
$$

Once a match occurs, the surplus over which bargaining takes place is given by

$$
\begin{array}{r}
\Pi(t)=\int_{t}^{t+T(t)}\left[A(t)-\left(\tilde{w}^{D}(s)-b(s)\right) A(s)\right] e^{-(r+\delta)(s-t)} d s \\
-(1-\phi) I_{H} A(t) .
\end{array}
$$

The surplus is equal to the expected present value of the cash flow received from the job over its lifetime - equal to output $A(t)$ minus the intermediate input cost $p(s) A(s)$ plus the subsidy $z(s) A(s)$ - from which we must subtract the utility flow $\tilde{w}^{D}(s) A(s)$ foregone by the worker and the fraction of setup costs $(1-\phi) I_{H}$ that is either not match-specific 
or can be bonded away.

The surplus is first maximized to find the maximum planned lifetime $T(t)$ of the job, and then bargained over. It is easy to see that the first order condition from maximization is

$$
A(t)-\left[\tilde{w}^{D}(t+T(t))-b(t+T(t))\right] A(t+T(t))=0 .
$$

It can be thought of as an exit condition, and states that, at the time of exit $t+T(t)$, the quasi-rents from the job should be zero. Finally the surplus is shared, with fractions $\beta$ and $(1-\beta)$ going to the worker and the firm:

$$
\begin{gathered}
W^{e}(t)-W^{u}(t)=\beta \Pi(t) \\
W^{f}(t)=(1-\beta) \Pi(t) .
\end{gathered}
$$

Equations (14)-(15) in the main text are obtained as follows. Equation (14) is derived using (29) and (33) from the exit condition (32), which can be written in terms of $\bar{a}(t)$ using (11):

$$
A(t-\bar{a}(t))-\left[\tilde{w}^{D}(t)-b(t)\right] A(t)=0
$$

Equation (15) is the free entry condition (28), taking (31), (34) and (35) into account.

\section{A.2 $(\phi, \beta)$-Equivalence in Steady State}

In this section we prove the steady-state equivalence result between $\phi$ and $\beta$ stated in section 4.1. For any steady state $\left(\bar{a}_{0}^{*}, H_{0}^{*}, U_{0}^{*}\right)$, we must determine the corresponding equivalence schedule $(\phi, \beta)=\left(\phi, f_{0}(\phi)\right)$ along which the steady state remains unchanged. From equations (18)-(19) we know that for this to happen $\tilde{w}^{-D}$ and $\tilde{c}^{D}$ must be constant along those schedules. 
Now, replacing $(21)$ in $(22)$ yields

$$
\widetilde{c}^{-D}=I_{H}^{*}+S^{*}+\tilde{w}^{* D} \frac{U^{*}}{H^{*}}
$$

This means that a schedule $\left(\phi, f_{0}(\phi)\right)$ that keeps $\tilde{w}^{* D}$ constant given $\left(\bar{a}_{0}^{*}, H_{0}^{*}, U_{0}^{*}\right)$ also keeps $\mathfrak{c}^{D}$ constant. This schedule can be easily obtained by inverting (21) and solving for the wage in (18):

$$
f_{0}(\phi)=\left[1+\frac{H^{*}}{U^{*}}\left(\frac{\phi I_{H}^{*}+S^{*}}{b^{*}+e^{-\gamma^{*}}}\right)\right]_{\left(\bar{a}^{*}, H^{*}, U^{*}\right)=\left(\bar{a}_{0}^{*}, H_{0}^{*}, U_{0}^{*}\right)}^{-1}
$$

\section{A.3 The Weak- and Strong-Worker Regions: Characterization}

In this section we show that, in steady-state equilibrium, an increase in workers' bargaining power (i) lowers the probability $X^{*} \equiv H^{*} / U^{*}$ of the unemployed finding a job, (ii) lowers the scrapping age $\vec{a}^{*}$ if the worker is weak, but raises it if he is strong, and (iii) raises unemployment. Given the equivalence result in section A.2, without loss of generality we set $\phi=0$ in the proof of those statements.

Replacing $\tilde{w}^{\bullet D}$ from (21) in the exit condition (18), and differentiating, yields

$$
-\gamma e^{-\gamma \boldsymbol{\alpha}^{*}} d \vec{a}=\frac{\beta S^{*}}{(1-\beta)(1-\eta)} d X^{*}+\frac{X^{*} S^{*}}{(1-\beta)^{2}} d \beta
$$

Replacing $\vec{c}^{D}$ from (22) in the free-entry condition (19), and differentiating, yields

$$
P V^{\prime}\left(\bar{a}^{*}\right) d \vec{a}=\frac{S^{*}}{(1-\beta)^{2}} d \beta+\frac{\eta}{1-\eta} \frac{S^{*} / X^{*}}{1-\beta} d X^{*}
$$

Solving out for $d \bar{a}^{*}$ from (36) and (37), we get

$$
\frac{d X^{*}}{d \beta}=-\frac{X^{*}(1-\eta)\left[P V^{\prime}\left(\bar{a}^{*}\right) X^{*}+\gamma e^{-\gamma \bar{a}^{*}}\right]}{\eta(1-\beta)\left[(\beta / \eta) P V^{\prime}\left(\bar{a}^{*}\right) X^{*}+\gamma e^{-\gamma^{*}}\right]},
$$

which is strictly negative since $P V^{\prime}\left(\bar{a}^{*}\right)>0$. 
Solving out for $d X^{*}$ rather than $d \vec{a}^{*}$ from (36) and (37), we get

$$
\frac{d \bar{a}^{*}}{d \beta}=\frac{S^{*} X^{*}(\beta-\eta)}{(1-\bar{\beta})^{2}\left[\beta X^{*} P V^{\prime}(\bar{a})+\eta \gamma e^{-\gamma^{*}}\right]}
$$

Thus, $\vec{d}^{*}$ is decreasing (resp. increasing) with respect to worker power when workers are weak (resp. strong), reaching a minimum at the efficient point.

As for unemployment, differentiating (20) we have

$$
\frac{d U^{*}}{d \beta}=-U^{2}\left[\frac{1-e^{-\delta \bar{a}^{*}}}{\delta} \frac{d X^{*}}{d \beta}+X^{*} e^{-\delta \bar{a}^{*}} \frac{d \bar{a}^{*}}{d \beta}\right]
$$

This expression is clearly positive in the weak-worker region, since both $X^{*}$ and $\vec{a}^{*}$ are decreasing with respect to worker power. In the strong-worker region, this expression is more difficult to sign. All the numerical examples we have tried show $U^{*}$ rising with $\beta$ throughout the region, but we could not prove this in general. What we can show is that $d U^{*} / d \beta$ is positive near $\beta=\eta$ (because there $d X^{*} / d \beta>0$ and $d \bar{a}^{*} / d \beta \approx 0$ ), and that $U^{*} \rightarrow L$ as $\beta \rightarrow 1$ (because the effective creation cost goes to infinity while the present value of the quasi-rents is bounded from above by $1 /(r+\delta)<\infty)$.

\section{A.4 Steady-State Welfare}

This appendix derives (i) expression (24) for steady-state welfare in terms of factor income streams; and (ii) espression (26) for the effect of policy on the steady-state flow of welfare in the limit case when $r \rightarrow \gamma$.

Replacing the accounting identities (4) and (5) in the social planner's objective function yields welfare at time $t$ :

$$
W(t)=\int_{l}^{\infty}[Q(s)-C(s) A(s)+p(s) A(s)(\bar{M}-E(s))] e^{-r(a-t)} d s,
$$


which can be re-written as

$$
W(t)=A(t) \int_{1}^{\infty}[q(s)-C(s)+p(s)(M-E(s))] e^{-(r-\gamma)(s-t)} d s .
$$

Using the expressions for output and employment, separating out the use and output of factors committed before time $t$, adding and subtracting wages, subsidies and effective costs, using the free-entry and exit conditions, and rearranging, yields

$$
\begin{gathered}
\frac{W(t)}{A(t)}=\int_{t}^{t+T(t)} \int_{s-1}^{\mathrm{\tau}(s)}\left(e^{-\gamma a}-e^{-\gamma \bar{a}(\lrcorner)}\right) e^{-\delta a} d a e^{-(r-\delta)(s-t)} d s+ \\
\int_{t}^{\infty}\left[p(s) M+\left(\tilde{w}^{D}-z(s)\right) E(s)+\left(\tilde{c}^{D} H(s)-C(s)\right)\right] e^{-(r-\gamma)(s-t)} d s .
\end{gathered}
$$

Using the fact that,

$$
C(s)=\tilde{c}^{D}(s) H(s)-\tilde{w}^{D}(s) U(s)-\frac{1}{2} I_{H H} H(s)^{2}+i(s) H(s)
$$

assuming the economy is in steady-state, and setting $A(0)=1$, transforms (38) into

$$
W^{*}=K_{0}+\frac{p \bar{M}+\tilde{w}^{* D} \bar{L}+\frac{1}{2} I_{H H} H^{* 2}-z^{*}\left(L-U^{*}\right)-i^{*} H^{*}}{r-\gamma}
$$

which corresponds to (24), expanded to include production and creation incentives and rents due to decreasing returns to scale in $I(H)$. The rent $K_{0}$ accruing to the factors in use at the time of computing welfare is

$$
K_{0} \equiv \frac{1-e^{-(r+\delta) \bar{a}^{*}}}{(r+\delta)(\delta+\gamma)}-\frac{e^{-(\delta+\gamma) \bar{a}^{*}}-e^{-(r+\delta) \vec{a}^{*}}}{(r-\gamma)(\delta+\gamma)}-\frac{e^{-\gamma \bar{a}^{*}}-e^{-(r+\delta) \bar{a}^{*}}}{(r+\delta-\gamma) \delta}+\frac{e^{-(\delta+\gamma) \bar{a}^{*}}-e^{-(r+\delta) \bar{a}^{*}}}{(r-\gamma) \delta}
$$

Setting $I_{H H}=0$, and defining the undiscounted welfare flow as $\omega^{*} \equiv \lim _{r} \backslash \gamma(r-\gamma) W^{*}$, we obtain

$$
\omega^{*}=p \bar{M}+\tilde{\boldsymbol{w}}^{* D} \bar{L}-z^{*}\left(\bar{L}-U^{*}\right)-i^{*} H^{*}
$$


Alternatively,

$$
\omega^{*}=q^{*}-C^{*}+p \bar{M}-p\left(\bar{L}-U^{*}\right),
$$

which can be differentiated to yield

$$
d \omega^{*}=\left(g_{H}-C_{H}\right) d H+\left(g_{U}+p-C_{U}\right) d U
$$

It is easy to verify that, in steady-state with $r=\gamma$, we have $q_{H}=\tilde{c}^{D}-i$ and $q_{U}=\tilde{w}^{\cdot D}-z$. Replacing those expressions in (39), and recalling $\tilde{c}^{-S}=C_{H}^{\bullet}$ and $\tilde{w}^{* S}=-C_{\dot{U}}^{*}$, yields

$$
d \omega^{*}=\left(\tilde{c}^{D}-i^{*}-\vec{c}^{S}\right) d H-\left(\tilde{w}^{* D}-z^{*}-\tilde{w}^{* S}\right) d U
$$

This immediately implies expression (26).

\section{A.5 Effects of Production and Creation Incentives}

This appendix analyzes the steady-state effect of production and creation incentives on the hiring intensity, unemployment and the scrapping age.

Production Incentives. Assuming $z^{*}=I_{H H}^{*}=0$ and letting $X^{*} \equiv H^{*} / U^{*}$, we can differentiate (18) and (19) with respect to $z^{*}$ to obtain

$$
\frac{d \bar{a}^{*}}{d z^{*}}=\frac{e^{\gamma \bar{\sigma}^{*}}}{\gamma}\left\{1-\frac{\beta}{1-\beta}\left(\phi I_{H}^{*}+\frac{S^{*}}{1-\eta}\right) \frac{d X^{*}}{d z^{*}}\right\}
$$

and

$$
\frac{d X^{*}}{d z^{*}}=\frac{1-\eta}{\eta} \frac{X^{*}}{S^{*}} P V^{\prime}\left(\bar{a}^{*}\right)(1-\beta) \frac{d \bar{a}^{*}}{d z^{*}}
$$

Since

$$
P V^{\prime}\left(\bar{a}^{*}\right)=\frac{\gamma}{r+\delta-\gamma}\left(e^{-\gamma^{\bar{a}^{*}}}-e^{-(r+\delta) \bar{a}^{*}}\right)>0
$$


equation (41) implies

$$
\operatorname{sgn}\left(\frac{d \vec{a}}{d z^{*}}\right)=\operatorname{sgn}\left(\frac{d X^{*}}{d z^{*}}\right)
$$

But this condition is only consistent with (40) if

$$
\frac{d X^{*}}{d z^{*}}>0 \text { and } \quad \frac{d \vec{a}}{d z^{*}}>0
$$

Using this result and differentiating equation (20) shows that unemployment decreases with the subsidy $z^{*}$ :

$$
\frac{d U^{*}}{d z^{*}}=-U^{* 2}\left\{\left(1-e^{-\delta \bar{\sigma}^{*}}\right) \frac{d X^{*}}{d z^{*}}+\delta X^{*} e^{-\delta a^{*}} \frac{d a^{*}}{d z^{*}}\right\}<0 .
$$

Creation Incentives. Replacing (21) in (18) and differentiating the resulting expression with respect to $i *$ yields

$$
\frac{d a^{*}}{d i^{*}}=-\frac{e^{\gamma^{*}}}{\gamma} \frac{\beta}{1-\beta}\left[\phi I_{H}^{*}+\frac{S^{*}}{1-\eta}\right] \frac{d X^{*}}{d i^{*}}
$$

Subtracting $i^{-}$from the left-hand side of (22), substituting the resulting expression in (19), differentiating the outcome with respect to $i^{\bullet}$, and substituting $d \bar{a}^{*} / d i^{*}$ from (42) yields

$$
\frac{d X^{*}}{d i^{*}}=\frac{1-\beta}{S^{* 1}+\beta\left[\phi I_{H}+S^{*} /(1-\eta)\right]\left(1-e^{-\delta \tilde{a}^{*}}\right) / \delta}>0 .
$$

This, in conjunction with (42), implies:

$$
\frac{d \vec{a}}{d i^{*}}<0
$$

Finally, as illustrated in figure 9 , the response of unemployment to creation incentives cannot be signed. 


\section{References}

[1] Abraham, Katherine, and Lawrence Katz (1986): "Cyclical Unemployment: Sectoral Shifts or Aggregate Disturbances?" Journal of Political Economy, 94, pt. 1, 507-522.

[2] Aghion, Philippe, and Peter Howitt (1992a): "A Model of Growth through Creative Destruction," Econometrica, 60, 323-352.

[3] - (1992b): "Growth and Unemployment," typescript, University of Western Ontario, May.

[4] Aghion, Philippe, and Gilles Saint-Paul (1991): "On the Virtue of Bad Times," typescript.

[5] Baily, Martin Neil, Charles Hulten and David Campbell (1992): "Productivity Dynamics in Manufacturing Plants," Brookings Papers on Economic Activity: Microeconomics, 187-267.

[6] Bartelsman, Eric J., and Phoebius J. Dhrymes (1991): "Productivity Dynamics: U.S. Manufacturing Plants, 1972-1986, ${ }^{n}$ Columbia University Department of Economics Discussion Paper No. 584, September.

[7] Binmore, Ken, Ariel Rubinstein and Asher Wolinsky (1986): "The Nash Bargaining Solution in Economic Modeling," Rand Journal of Economics, 17, 176-188.

[8] Blanchard, Olivier, and Peter Diamond (1989): “The Beveridge Curve," Brookings Papers on Economic Activity, 2, 85-155.

[9] —_ (1990): "The Cyclical Behavior of Gross Flows of Workers in the U.S.," Brookings Papers on Economic Activity, 2, 85-155.

[10] Bresnahan, Timothy F., and Daniel M. G. Raff (1991): "Intra-Industry Heterogeneity and the Great Depression: The American Motor Vehicles Industry, 1929-35," Journal of Economic Bistory, 51, 317-331. 
[11] - (1992): "Technological Heterogeneity, Adjustment Costs, and the Dynamics of Plant-Shut-Down Behavior: The American Motor Vehicle Industry in the Time of the Great Depression," typescript, Stanford University.

[12] Caballero, Ricardo J., and Mohamad L. Hammour (1994): "The Cleansing Effect of Recessions," American Economic Review, forthcoming.

[13] Cohen, Daniel, and Gilles Saint-Paul (1994): "Uneven Technical Progress and Job Destruction," typescript.

[14] Cooper, Russell, and John Haltiwanger (1993): "The Aggregate Implications of Machine Replacement: Theory and Evidence," American Economic Review, 83, $360-380$.

[15] Cox, W. Michael (1993): "Technological Unemployment," Federal Reserve Bank of Dallas, Research Paper \#9314, June.

[16] — and Richard Alm (1993): "The Churn," Federal Reserve Bank of Dallas, 5-18.

[17] Davis, Steven J. (1987): "Fluctuations in the Pace of Labor Reallocation," CarnegieRochester Conference Series on Public Policy, 27, 335-402.

[18] _ـ and John Haltiwanger (1990): "Gross Job Creation and Destruction: Microeconomic Evidence and Macroeconomic Implications," NBER Macroeconomics Annual, 5, 123-168.

[19] - (1992): "Gross Job Creation, Gross Job Destruction and Employment Reallocation," Quarterly Journal of Economics, 107, 819-864.

[20] - (1994): "Driving Forces and Employment Fluctuations: New Evidence and Alternative Interpretations," typescript, January.

[21] DeLong, J. Bradford (1990): "Liquidation Cycles: Old Fashioned Real Business Cycle Theory and the Great Depression," NBER Working Paper No. 3546. 
[22] Diamond, Peter (1982): "Wage Determination and Efficiency in Search Equilibrium," Review of Economic Studies, 49, April, 217-227.

[23] - (1994): "On Time," typescript, MIT.

[24] Gali, Jordi, and Mohamad L. Hammour (1992): "Long Run Effects of Business Cycles," typescript.

[25] Greenwood, Jeremy, Zvi Herkowitz and Per Krusell (1992): "Macroeconomic Implications of Investment-Specific Technological Change," typescript, Institute for International Economic Studies Seminar Paper No. 527, October.

[26] Grossman, Gene M., and Elhanan Helpman (1991): Innovation and Growth in the Global Economy, Cambridge: MIT Press.

[27] Grout, Paul A. (1984): "Investment and Wages in the Absence of Binding Contracts: A Nash Bargaining Approach," Econometrica, 52-2, March, 449-460.

[28] Hopenhayn, Hugo, and Richard Rogerson (1991): "Job Turnover and Policy Evaluation: A General Equilibrium Analysis," typescript.

[29] Hall, Robert E. (1991): "Labor Demand, Labor Supply, and Employment Volatility," NBER Macroeconomics Annual, 6, 17-47.

[30] Hosios, Arthur J. (1990): "On the Efficiency of Matching and Related Models of Search and Unemployment," Review of Economic Studies, 57, 279-298.

[31] Hulten, Charles R. (1992): "Growth Accounting when Technical Change is Embodied in Capital," American Economic Review, 82, 964-980.

[32] Johansen, Leif (1959): "Substitution versus Fixed Production Coefficients in the Theory of Economic Growth: A Synthesis," Econometrica, 27, 157-76.

[33] Jovanovic, Boyan, and Saul Lach, "Entry, Exit, and Diffusion with Learning by Doing," American Economic Review, September 1989, 79, 690-699. 
[34] Katz, Lawrence F. (1987): "Efficiency Wage Theories: A Partial Evaluation," NBER Macroeconomics Annuah, 1, 235-276.

[35] Lilien, D. M. (1982): "Sectoral Shifts and Cyclical Unemployment," Journal of Political Economy, 90, 777-793.

[36] Lucas, Robert E., and Edward Prescott (1974): "Equilibrium Search and Unemployment," Journal of Economic Theory, 7, 188-209.

[37] Mortensen, Dale (1978): "Specific Capital and Labor Turnover," Bell Journal of Economics 9 Autumn, 572-586.

[38] - (1992): "The Cyclical Behavior of Job and Worker Flows," typescript, Northwestern University, July.

[39] __ and Christopher Pissarides (1992): "The Cyclical Behavior of Job Creation and Job Destruction," typescript, January.

[40] Phelps, Edmund S. (1963): "Substitution, Fixed Proportions, Growth and Distribution," International Economic Review, 4, 265-288.

[41] Pissarides, Christopher (1990): Equilibrium Unemployment Theory, Oxford: Basil Blackwell.

[42] Saint-Paul, Gilles (1993): "Productivity Growth and the Structure of the Business Cycle," European Economic Review.

[43] Salter, Wilfred E.G. (1960): Productivity and Technical Change, Cambridge: Cambridge University Press.

[44] Schumpeter, Joseph A. (1942): Capitalism, Socialism, and Democracy, New York: Harper and Brothers.

[45] Shapiro, C. and J.E. Stiglitz (1984): "Equilibrium Unemployment as a Discipline Device," American Economic Review 79(9), June, 433-444. 
[46] Sheshinski, Eytan, "Balanced Growth and Stability in the Johansen Vintage Model," Review of Economic Studies, 1967, 34, 239-248.

[47] Solow, Robert M. (1960): "Investment and Technological Progress," in K.J. Arrow, S. Karlin and P. Suppes (eds.), Mathematical Methods in Social Sciences, Stanford University Press, 89-104.

[48] Stiglitz, Joseph (1993): "Endogenous Growth and Cycles," NBER Working Paper No. 4286, March.

[49] Young, Alwyn (1992): "A Tale of Two Citjes: Factor Accumulation and Technical Change in Hong Kong and Singapore," NBER Macroeconomics Annual, 7, 13-53. 